\title{
Aufsatz
}

Joachim Krause*

\section{Kriege und Kriegsgefahren im kommenden Jahrzehnt}

https://doi.org/10.1515/sirius-2020-2002

Zusammenfassung: Der Artikel befasst sich mit den Möglichkeiten der Vorhersage von Kriegen und deren wahrscheinlichen Verläufen. Zwar lassen sich Kriege in den seltensten Fällen konkret vorhersagen, aber anhand von zwei bereits von Clausewitz genannten Indikatoren kann man zumindest eine erhöhte Kriegswahrscheinlichkeit feststellen: wenigstens ein Akteur muss den Willen zum Krieg aufweisen und er muss die dazu benötigten Rüstungsaufwendungen tätigen. Auch lassen sich Abläufe von Kriegen in Kenntnis der vorhandenen Waffen und Doktrinen auf mögliche Szenarien reduzieren. Der Beitrag gelangt zu dem Ergebnis, dass im nächsten Jahrzehnt ein großer Krieg am ehesten um die Kontrolle von Taiwan ausbrechen könnte oder um die Verfügungsgewalt des Irans über Kernwaffen. Zudem muss mit regional begrenzten Kriegen in Europa gerechnet werden, die von Russland ausgehen. Das denkbar unangenehmste Szenario würde eintreten, wenn Russland und China sich verabreden zum gleichen Zeitpunkt regionale Kriege an ihren Peripherien anzufangen.

Schlüsselbegriffe: Krieg, Kriegswahrscheinlichkeit, Russland, China, Iran, Israel, Taiwan

\begin{abstract}
This article addresses ways and means to predict the outbreak of wars and the likely course of such wars. In most cases, it is not possible to predict the outbreak of a war, but there are two indicators named already by Clausewitz, which can help to assess a high probability of such an event: the existence of the will to initiate war, at least at one side, and the concomitant build-up of a military posture. While it is usually not possible to predict the course and outcome of a war, one can at least devise some possible scenarios for the outcome of a war as long as one knows the relevant arms, doctrines and enablers. The article arrives at the conclusion that in the coming decade the biggest danger of war is associated with the Chinese
\end{abstract}

*Kontakt: Prof. Dr. Joachim Krause, ISPK, E-Mail: jkrause@politik.uni-kiel.de quest for a forceful "re-unification" with Taiwan and the associated danger of a regional war between the U.S. and China. In another theatre, the Iranian nuclear weapons program may lead to a nuclear war in the Middle East. Of great concern is also the Russian tendency to envision regional wars in Europe (in particular against the Ukraine and the Baltic states). The biggest challenge for the West would be a concerted action by Russia and China during which regional wars in East Asia and Europe are being started at the same time.

Keywords: War, probability of wars, Russia, China, Iran, Israel, Taiwan

\section{Einleitung}

In der deutschen wie in der internationalen politischen Debatte wird häufig auf die Gefahr von Kriegen verwiesen. Das Bulletin of Atomic Scientists bildet schon seit Jahrzehnten auf seinem Titelblatt eine Uhr ab, die suggeriert, dass es „kurz vor zwölf“ sei und die Gefahr eines großen Krieges geradezu mit den Händen greifbar sei. Deutsche Politiker und Politikerinnen warnen gerne vor der Eskalation regionaler Konflikte, vor „Flächenbränden“ unterschiedlicher Natur, vor „Rüstungswettläufen mit katastrophalem Ausgang“ und vor „Atomkriegen aus Versehen“ oder aufgrund von Missverständnissen. In der Regel werden gerne Assoziationen mit dem Ausbruch des Ersten Weltkrieges vorgenommen. Seit dem Erscheinen des Buches von Christopher Clark über den Ausbruch des Ersten Weltkriegs wird auch gerne die Metapher des „Schlafwandelns“ gebraucht, mit der zum Ausdruck gebracht werden soll, dass Staaten sich durch ihre Verteidigungspolitik in eine Konstellation hineinbewegten, in der der Ausbruch eines Krieges kaum zu vermeiden sei. ${ }^{1}$ Gleiches gelte es heute $\mathrm{zu}$ verhindern, indem auf die Gefahr von Kriegen hingewiesen wird. Dabei werden oft Assoziationen mit dem Zweiten Weltkrieg oder mit der Zeit der militärischen Konfrontation während des Ost-West-Konfliktes geweckt.

1 Clark 2013. 
Während es natürlich zu begrüßen ist, wenn deutsche Politiker und Politikerinnen sich für De-Eskalation und Vernunft aussprechen, so ist nicht zu übersehen, dass die Häufung dieser Mahnungen und das Nicht-Eintreten der prophezeiten Flächenbrände oder Kriege in einem gewissen Missverhältnis zueinander stehen. Tatsächlich sollte man die Frage stellen: Stehen wir wirklich vor Situationen, die der Vorphase des Ersten Weltkriegs (oder gar des Zweiten Weltkriegs) ähneln? Wenn das der Fall ist, wie erklärt sich dann die Abwesenheit weiterer großer Kriege? Der Zweite Weltkrieg ist jetzt seit 75 Jahren vorüber, das ist die längste Friedensperiode der europäischen Geschichte. Was hat sich geändert gegenüber der Zeit vor dem Ersten Weltkrieg? Und wie stellt sich die Gefahr von Kriegen in den kommenden Jahren wirklich dar? Welche Anzeichen gibt es dafür, dass Kriege ausbrechen könnten?

Im Folgenden werden in einem ersten Schritt die Mängel der vorherrschenden Debatte aufgegriffen, angefangen vom undifferenzierten Gebrauch des Wortes „Krieg“ bis hin zu den häufigsten Fehlperzeptionen. In einem weiteren Schritt wird danach gefragt, welches unter den heute diskutierten und vorstellbaren Kriegsszenarien im kommenden Jahrzehnt realen Charakter hat und welches nicht. Ausgangspunkt dafür ist die Befassung mit den materiellen und politischen Voraussetzungen (aber auch Begrenzungen) der unterschiedlichen Formen von Kriegen. Kriege finden nur dann statt, wenn das dazu notwendige Maß an Feindseligkeit oder Entschlossenheit besteht, das heißt, wie weit politische Führer und die sie stützenden politischen Kräfte und Koalitionen bereit sind, Gewalt zur Verfolgung der von ihnen verfolgten Interessen oder Werte einzusetzen. Und der Verlauf eines Krieges hängt immer davon ab, wer welche Waffen auf welchem Raum zur Verfügung hat. Anders ausgedrückt: In einem Krieg - vor allem in den ersten Tagen, Wochen und Monaten - kann immer nur das geschehen, worauf sich die daran beteiligten Parteien in den Jahren zuvor vorbereitet haben (Waffen, Menschen, Material, Doktrinen, Munitionsbevorratung, Führungsorganisation, Mobilisierung). Hinzu kommt, dass Kriege immer eine Dynamik entwickeln, von der schon Clausewitz schrieb, dass keiner ihren Verlauf sicher vorhersehen könne. ${ }^{2}$ Tatsächlich haben viele - aber nicht alle - Kriege in der Geschichte erkennen lassen, dass der Verlauf der kriegerischen Handlungen anders vonstattenging als vorhergesehen. Dazu gehören nicht nur die Entwicklungen auf dem „Schlachtfeld“ (oder dem „Kriegstheater“ oder „Kriegsschauplatz“, wie man besser sagen sollte), sondern auch die politischen

2 Clausewitz 1867, 45 (Erstes Buch, Kapitel 3).
Auseinandersetzungen in den Hauptstädten der kriegführenden Parteien. Die Dynamik künftiger kriegerischer Auseinandersetzungen lässt sich nicht immer vorhersehen, aber sie lässt sich zumindest bis zu einem gewissen Grad strukturieren (auch mit unterschiedlichen Szenarien des Ausgangs).

\section{Defizite der politischen wie der wissenschaftlichen Debatte}

Die oben konstatierte Aufgeregtheit im Umgang mit „Kriegen“ ist nachvollziehbar angesichts der deutschen Alleinverantwortung für den Ausbruch des Zweiten und der deutschen Mitverantwortung für den Ausbruch des Ersten Weltkriegs und der damit verbundenen traumatischen Erfahrungen mehrerer Generationen. Die damit einhergehende Abneigung, sich überhaupt mit kriegerischen Auseinandersetzungen im Detail zu befassen, ist allerdings problematisch, denn sie führt zu einer strategischen Blindheit. Diese Blindheit bedeutet, dass militärische Risiken und Gefahren nicht mehr adäquat abgebildet und politisch erörtert werden können. Das wird im heutigen Deutschland leider immer mehr zur Regel: Die deutsche Politik und die vorherrschenden Medien sind immer weniger in der Lage, sich jenseits von Allgemeinplätzen und Betroffenheitsäußerungen differenziert mit Fragen von Krieg und Frieden auseinanderzusetzen.

Der undifferenzierte Gebrauch des Begriffs „Krieg“ ist allerdings nicht auf Deutschland beschränkt. Es ist auch international üblich geworden, alle Formen organisierter gewaltsamer Auseinandersetzungen unter dem Begriff „Krieg“ zu subsummieren. Für statistische Zwecke mag das ausreichen, aber eine strategisch relevante Auseinandersetzung mit den unterschiedlichen Formen von Kriegen muss anders vorgehen, insbesondere dann, wenn man Kriegsgefahren einschätzen will. Das wird erkennbar, wenn man die Klagen über den „Afghanistan-Krieg“ hört, der der „längste Krieg in der amerikanischen Geschichte“ sei. Das ist im Hinblick auf die Zeitspanne zwar korrekt, aber die Zahl der amerikanischen Todesopfer bleibt ebenso gering wie das generelle Gewaltniveau im Vergleich $\mathrm{zu}$ anderen Kriegen, sei es der Zweite Weltkrieg oder der Vietnamkrieg. ${ }^{3}$ Die Länge eines Krieges sagt noch

3 Im zweiten Weltkrieg starben etwa 418.000 Amerikaner, auf dem Höhepunkt des Vietnamkrieges starben im Durchschnitt 50 Amerikaner pro Tag, am Ende waren es 55.000 Gefallene. In Afghanistan sind im Jahr 201922 tote Amerikaner zu beklagen gewesen, vgl. Stars and Stripes, 1.1.2020. Laut einer Aufstellung des Congressional Re- 
Tab. 1: unterschiedliche Kriegstypen

\begin{tabular}{|c|c|}
\hline 1. Klassische, geradezu unbegrenzte feudale Kriege & $\begin{array}{l}\text { 14. Bürgerkriege zwischen ethnischen oder religiösen } \\
\text { Gemeinschaften }\end{array}$ \\
\hline 2. Klassische Kabinettskriege & $\begin{array}{l}\text { 15. Bürgerkriege, bei denen es um die Abspaltung bestimmter } \\
\text { Gebiete von einem Gesamtstaat geht }\end{array}$ \\
\hline 3. Kriege zur imperialen Eroberung & $\begin{array}{l}\text { 16. Bürgerkriege, bei denen die Regierung gegen organisierte Krimi- } \\
\text { nalität kämpft }\end{array}$ \\
\hline 4. Klassische Volkskriege gegen Besatzer & 17. Bürgerkriege mit einer sich selbst verstetigenden Kriegsökonomie \\
\hline 5. Nationale Einigungskriege & 18. Anti-Zivilisations-Kriege \\
\hline $\begin{array}{l}\text { 6. Große internationale Kriege unter Industrienationen } \\
\text { (Weltkriege) }\end{array}$ & 19. Religionskriege \\
\hline $\begin{array}{l}\text { 7. Größere internationale Kriege unter Schwellenstaaten und } \\
\text { Entwicklungsländern }\end{array}$ & $\begin{array}{l}\text { 20. Kriege gegen extremistische oder terroristische Organisationen, } \\
\text { die die Kontrolle über ein Territorium übernommen haben und dort } \\
\text { Staatlichkeit aufbauen wollen }\end{array}$ \\
\hline 8. Begrenzte Kriege um Territorien und Grenzverläufe & $\begin{array}{l}\text { 21. Kriege zur Vernichtung anderer Länder oder Völker (Vernichtungs- } \\
\text { kriege) }\end{array}$ \\
\hline 9. Kriege über die Kontrolle maritimer Gebiete oder Inseln & $\begin{array}{l}\text { 22. Kriege, die von Staaten unter einem Mandat der kollektiven } \\
\text { Sicherheit geführt werden }\end{array}$ \\
\hline 10. Postmoderne hybride und politische Kriege & $\begin{array}{l}\text { 23. Begrenzte militärische Operationen, meist unter einem Mandat } \\
\text { kollektiver Sicherheit, die das Ziel haben einen bestimmten Staat oder } \\
\text { ein bestimmtes Territorium zu stabilisieren }\end{array}$ \\
\hline 11. Erziehungs- oder Bestrafungskriege & $\begin{array}{l}\text { 24. Zwischenstaatliche Kriege zum Sturz eines Regimes (mit oder } \\
\text { ohne Mandat kollektiver Sicherheit) }\end{array}$ \\
\hline $\begin{array}{l}\text { 12. Bürgerkriege, bei denen sich die Regierung einer Aufstands- } \\
\text { bewegung gegenübersieht }\end{array}$ & $\begin{array}{l}\text { 25. Präventivkriege zur Entwaffnung eines als gefährlich angesehe- } \\
\text { nen Staates }\end{array}$ \\
\hline
\end{tabular}

13. Bürgerkriege, in denen unterschiedliche politische Parteien über die politische Richtungsgebung des Landes streiten

Quelle: Krause 2019, 927-938

nichts über dessen Charakter aus, vor allem sagt sie nichts darüber aus, welche Ressourcen aufgewendet werden und welche Schäden und Verluste sie bereiten.

Tatsächlich müssen Kriege danach klassifiziert werden, wer wen mit welchen Mitteln und mit welcher Absicht angreift, in welchen Dimensionen sich dieser Krieg bewegt und wie hoch das Gewaltniveau ist. Der Verfasser hat an anderer Stelle eine Typologie von mindesten 25 unterschiedlichen Kriegsarten entwickelt, die von Großkriegen zwischen Industrienationen bis zu verschiedenen Bürgerkriegen reichen und die Erfahrungen der beobachteten Kriege der vergangenen Jahrhunderte

search Services ist die häufigste Todesursache unter amerikanischer Soldaten bei Verkehrsunfällen oder häuslichen Unfällen zu finden, dann kommen selbstverursachte Todesfälle (Selbstmord, Alkoholismus, Drogensucht), dann Erkrankungen und erst dann die Kategorie „killed in action“, vgl. Mann/Fischer 2019. widerspiegeln. ${ }^{4}$ Innerhalb dieser Typologie lassen sich auch Dynamiken von Kriegen besser verstehen und miteinander vergleichen. Jeder Kriegstypus tendiert zu unterschiedlichen Verläufen. Manche Kriege fallen in mehrere Kategorien bzw. innerhalb eines Krieges verändert sich dessen Charakter. Aber es ist sinnvoll, derartige Klassifikationen vorzunehmen, weil ansonsten der Begriff „Krieg“ undifferenziert gebraucht wird oder Differenzierungskategorien vorkommen, die wenig aussagekräftig sind wie die Bezeichnung „Neue Kriege“ oder „Krieg gegen den Terror".

In diesem Zusammenhang stellt sich auch die Frage, ob die Analogien zum Ausbruch des Ersten Weltkriegs angebracht sind. Die Situation von heute ist, zumindest was Europa betrifft, nicht mit derjenigen von 1914 vergleichbar. Im Jahr 1914 waren mehrere der beteiligten

4 Krause 2019. 


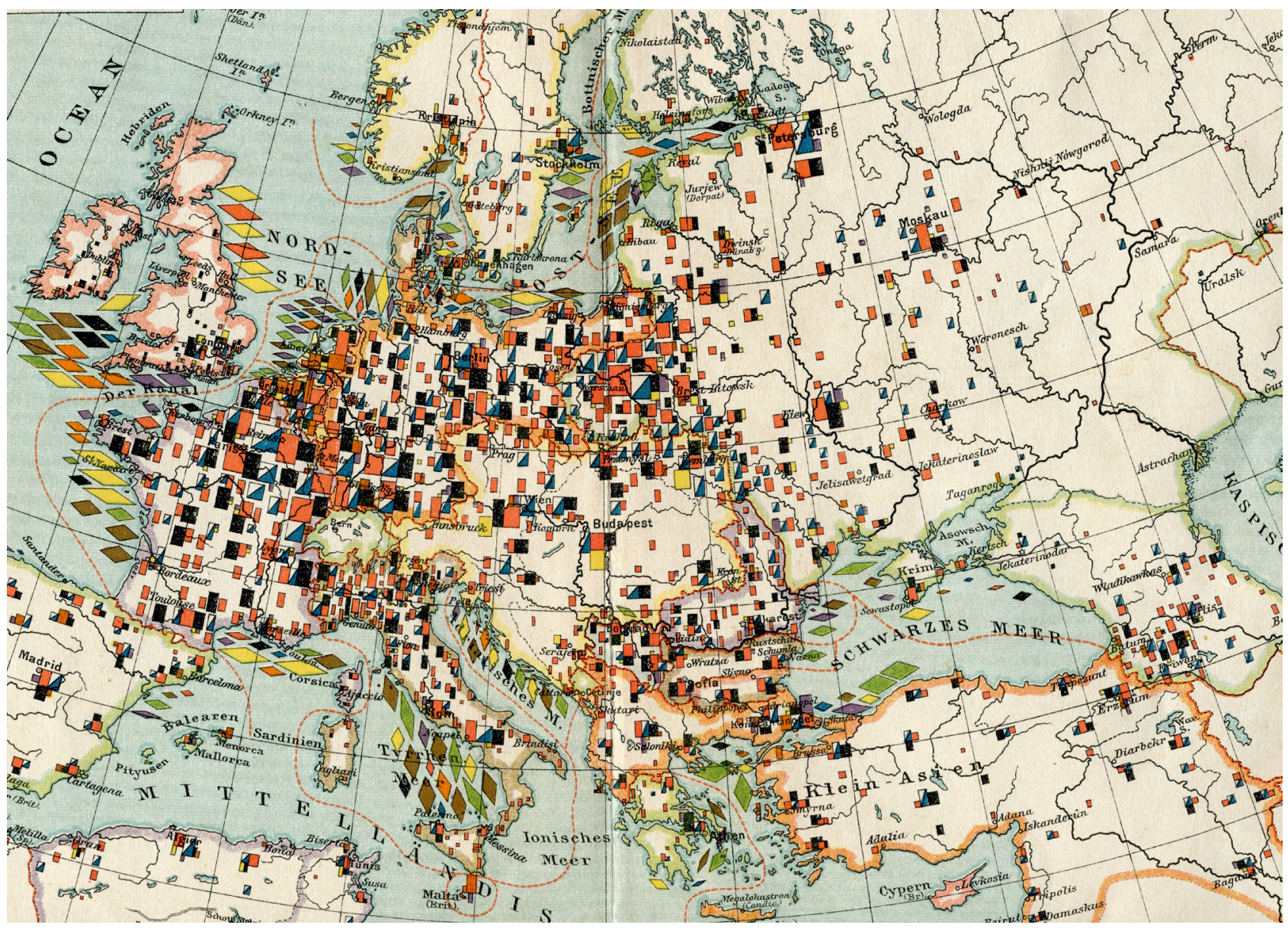

Die europäische Rüstungskonkurrenz um 1900 in einer zeitgenössischen Darstellung

Großmächte - insbesondere Deutschland, Frankreich, Russland, Österreich-Ungarn, weniger Großbritannien - voll der patriotischen Aufbruchstimmung. Vielen erschien „der Krieg“ als eine Erlösung, um endlich der jeweils anderen Seite das zu geben, was sie verdiene. ${ }^{5}$ Heute herrscht in europäischen Ländern weitgehend eine post-heroische Abneigung gegen alle Formen von Kriegen vor, lediglich in Russland findet sich eine von oben verordnete patriotische Mobilisierung wieder, die Anlass zur Sorge geben muss. Auch in anderen Krisenzonen der Welt gibt es heute kaum eine vergleichbare politisch-patriotische Mobilisierung, wenngleich es besorgniserregende Ansätze dazu in China gibt.

Zudem war die Rüstungskonkurrenz vor Ausbruch des Ersten Weltkrieges mit der heutigen Situation nicht zu vergleichen. Die Hauptgegner - Deutschland gegen

5 Wie Niall Ferguson aber zu Recht hinweist, war diese patriotische Stimmung keinesfalls ungeteilt; es gab sehr viele skeptische und kritische Stimmen und viel Furcht vor dem, was nun kommen würde, vgl. Ferguson 2001, 216-236.
Frankreich und Russland - verfügten schon in Friedenszeiten über umfangreiche Streitkräfte, die nach einer kurzen Mobilisierungsphase auf ein Mehrfaches der Friedenspräsenz anwachsen und aufgrund ihrer Invasionsfähigkeit und unter den gegebenen geografischen Bedingungen zu einer existenziellen strategischen Bedrohung für die jeweils andere Seite (Deutschland für Frankreich und Frankreich und Russland für Deutschland) werden konnten. Das Problem dabei war für alle beteiligten Seiten, wie man offensive Operationen unter schwerem Beschuss der anderen Seite (Artillerie, Maschinengewehrfeuer) durchführen sollte. ${ }^{6}$ In diesem Zusammenhang entstand ein Klima, in dem in Deutschland, Russland und Frankreich Pläne für Eroberungskriege entworfen wurden, mit denen die jeweils andere Seite strategisch besiegt werden sollte. ${ }^{7}$ Dazu gehörte auch der an das Schlieffen-Memorandum von 1906 angelehnte Aufmarschplan des Generalstabs unter

6 Strachan 2014, 70.

7 Vgl. hierzu Müller 2018. 
Helmut Moltke jr. gegen Frankreich, der im August 1914 zur Anwendung kam - und dann auf halben Weg scheiterte. ${ }^{8}$ Dieser Aufmarschplan hatte, wie ein Beobachter feststellte, etwas Verzweifeltes an sich und war sowohl der internationalen Einkreisungsfurcht geschuldet wie auch der Angst, dass es im Verlaufe eines langwieriges Krieges zu sozialen und politischen Verwerfungen kommen könne. ${ }^{9}$ Vergleichbare Situationen finden sich derzeit nirgendwo auf der Welt, wenngleich es Regionen gibt, in denen kriegerische Auseinandersetzungen denkbar sind - aber nicht solche, die die Dynamik des Ersten Weltkrieges entfalten könnten. Und die Geografie Europas wiederholt sich nicht, wo mit Frankreich und Deutschland zwei erbitterte Gegner auf engstem Raum zusammenstanden, die enorme wirtschaftliche Potentiale zur Fortsetzung des Krieges besaßen und die in der Lage waren ihren Konflikt zu globalisieren. ${ }^{10}$ Vor allem gibt es keine strategische Einkreisung eines relevanten Akteurs, die diesen zu ähnlich riskanten und eine Kriegsdynamik bestimmenden Maßnahmen veranlassen könnten wie es im Verhältnis Deutschlands zu Frankreich und Russland war. ${ }^{11}$ Der Sommer 1914 wird sich nicht wie-

8 In der Geschichtswissenschaft besteht eine heftige Kontroverse über die Relevanz der deutschen Kriegsvorbereitungen für den Ausbruch des Ersten Weltkriegs, die hier nicht aufgelöst werden kann. Während die Mehrzahl der Historiker davon ausgehen, dass es einen Kriegsplan („Schlieffenplan“) gegeben hätte, der der deutschen politischen Führung keine andere Option als den Angriff auf Frankreich als Antwort auf einen Krieg Russlands gegen Österreich-Ungarns lassen würde (z. B. Mombauer 2014, 105, Münkler 2015, 47), geht der amerikanische Militärhistoriker - und ehemalige Offizier - Terence Zuber davon aus, dass es keinen „Schlieffenplan“ gegeben habe und dass die deutsche Kriegsplanung zwar Rückgriffe auf Überlegungen Schlieffens gemacht habe, aber im Großen und Ganzen differenzierter gewesen sei (Zuber 2003). Zudem geht Zuber davon aus, dass Frankreich und Russland Deutschland strategisch eingekreist hätten und dadurch erst den Generalstab auf die Idee gebracht hätten, Pläne zu entwickeln, mit denen die strategische Offensive gesucht wurde, um aus einer hoffnungslosen Unterlegenheit herauszukommen. Siehe auch zu dieser Kontroverse die verschiedenen Beiträge in Ehlert/Epkenhans/Groß 2006.

9 Förster 1995, 80.

10 Krause 2014.

11 Zwar behaupten russische Politiker und Militärs wiederholt die angebliche militärische Einkreisung Russlands durch die USA und die NATO, diese Behauptung ist angesichts der Größe und der strategischen Tiefe Russlands jedoch abwegig. Zudem gibt es keine nennenswerten NATO-Streitkräfte in der Grenzregion Russlands. Außerdem hat sich Russland in Zentralasien einen cordon sanitaire geschaffen und mit China einen strategischen Partner, der ihm den Rücken freihält. Die Behauptung Russland sei von der NATO eingekreist ist genauso aberwitzig als wenn die USA behaupten würden, sie wären im Norden von Russland (Sibirien) und im Süden von Kuba und Venezuela eingekreist. Eine militärische Einkreisung liegt dann vor, wenn mit ihr eine direkte, existenzbedrohende militärische Invasionsgefahr einhergeht. derholen, ebenso nicht der September 1939, da es derzeit keinen Politiker vom Schlage eines Adolf Hitlers mit einer Partei wie der NSDAP gibt, die glauben, in einem bewusst herbeigeführten umfassenden Krieg Großräume für ihr Volk erobern zu müssen, andere Völker zu versklaven, Menschen jüdischen Glaubens oder Herkommens auszurotten und nebenbei den Kommunismus abzuschaffen. ${ }^{12}$

Wegen der Abwesenheit größerer Kriege sind in den vergangenen Jahren vornehmlich die „kleinen Kriege“ oder auch „neuen Kriege“ thematisiert worden. ${ }^{13}$ Tatsächlich gibt es eine Vielzahl von kleinen, regional begrenzten Kriegen - vornehmlich in Afrika und im Nahen und Mittleren Osten - sowie sonstige militärische Auseinandersetzungen, die zumeist innerhalb von Staaten stattfinden und sich in die oben erwähnten Kategorien einordnen lassen. Das Internationale Institut für Strategische Studien (IISS) zählte für das Jahr 2018 insgesamt 33 kriegerische, d. h. von Staaten oder von organisierten Gruppen gewaltsam ausgetragene Konflikte: davon 2 in Europa, 7 im Nahen Osten und Nordafrika, 9 in Afrika südlich der Sahara, 5 in Südasien, 5 in Ostasien und 5 in Lateinamerika. ${ }^{14}$ Pro Jahr dürften diese Konflikte über 150.000 Menschen das Leben kosten. Ob diese Kriege wirklich eine neue Form darstellen, wird in der wissenschaftlichen Debatte mehr und mehr bestritten. Die Beschäftigung mit kleinen Kriegen, insbesondere von Guerillakriegen ${ }^{15}$ und Bürgerkriegen innerhalb von Staaten mit begrenzter und defizitärer Staatlichkeit, ist schon sehr viel älterer Natur. Was neu sein dürfte, sind innerstaatliche bewaffnete Konflikte, an denen Akteure beteiligt sind, die nicht mehr erkennbar politische oder religiöse Ziele verfolgen, sondern eher opportunistisches Banditenwesen betreiben und deren Aktivitäten dennoch Folgewirkungen aufweisen, die denjenigen langanhaltender Kriege gleichkommen. ${ }^{16}$

Diese bewaffneten Konflikte und Kriege werden in der deutschen politischen Debatte weitgehend unter der Rubrik „fehlgeschlagene Staatlichkeit“ wahrgenommen und als Verteilungskonflikte, verursacht durch Ressourcenmangel und Klimawandel, dargestellt, die es durch Entwicklungshilfe zu beseitigen gelte. „Ausbleibende Entwicklung verschärft gesellschaftliche Konflikte,“ so der Bundesminister für Wirtschaftliche Zusammenarbeit, Gerd Müller, und der Vorsitzende der Münchener Sicherheitskonferenz, Wolfgang Ischinger, in einem Beitrag für die

12 Vgl. Müller 2004, 55 und 109f; siehe zu den entsprechenden Dokumenten mit den Absichten Hitlers auch Treue 1955.

13 Vgl. u. a. Kaldor 2012, Münkler 2002.

14 IISS 2019, 9.

15 Z.B. Heydte 1972, Hahlweg 1968.

16 Gettleman 2010, s. a. Newman 2004. 
Frankfurter Allgemeine Zeitung. ${ }^{17}$ Oder diese Kriege und Konflikte werden lediglich als Ursachen für Fluchtbewegungen angesehen und besonders dann aufmerksam verfolgt, wenn es Hinweise darauf gibt, dass deutsche Waffen in einem Konflikt Verwendung finden. ${ }^{18}$ Diese selektive Wahrnehmung, die häufig mit moralischem Rigorismus und einer gewissen Naivität bezüglich der Wirkungsweise von Entwicklungshilfe einhergeht, verstellt den Blick auf reale Herausforderungen und Probleme. Eine differenzierende Betrachtungsweise findet bestenfalls in Analysen spezialisierter Regionalexperten statt, die man noch in einschlägigen Forschungsinstitutionen und in Redaktionen von Zeitungen, Zeitschriften oder öffentlich-rechtlichen Medien finden kann.

Das gleiche Maß an Undifferenziertheit findet sich beim Gebrauch des Wortes „Rüstungswettlauf“. Die permanente Beschwörung dieser Gefahr soll suggerieren, dass man das sogenannte Sicherheitsdilemma im Auge hat - wer sich in defensiver Absicht rüstet, muss damit rechnen, dass seine Anstrengungen von anderer Seite als Bedrohung interpretiert wird und entsprechende Gegenrüstung bewirkt etc. ${ }^{19}$ Darauf zu achten ist nicht falsch, nur lässt sich nicht jede Konfliktsituation auf das Sicherheitsdilemma zurückführen. Auch gibt es bisher kein Beispiel dafür, dass ein Rüstungswettlauf einen Krieg ausgelöst hat. ${ }^{20}$ Zudem hat in der Politik der westlichen Allianz das Konzept schon lange Fuß gefasst, wonach Rüstungsmaßnahmen mit Rüstungskontrolle und Dialogangeboten zu verbinden sind.

\section{Methodische und politische Probleme der Bestimmung von Kriegsgefahr}

Kriege vorherzusagen, ist ein schwieriges Unterfangen. Es gab Kriege, die waren vorhersehbar (wie der erste isra-

17 Gerd Müller/Wolfgang Ischinger: Entwicklung und Sicherheit gehören zusammen, Frankfurter Allgemeine Zeitung, 14.2.2020.

18 Tatsächlich gibt es kaum Beispiele, wo deutsche Waffen in den oben genannten Konflikten zur Anwendung kommen. Die überwiegende Zahl der Waffen kommt aus ehemals sowjetischen, russischen, chinesischen, osteuropäischen und iranischen Beständen bzw. aus dem Schwarzmarkt, vgl. Krause 2018.

19 Der Begriff stammt aus dem 20. Jahrhundert und wurde zuerst von dem aus Deutschland stammenden US Politikwissenschaftler John Herz beschrieben, vgl. Herz 1950, 157.

20 Siehe das Buch von Mahncken/Maiolo/Stevenson 2016, eine Zusammenfassung der Ergebnisse des Buches findet sich bei Bamberger 2017. elisch-arabische Krieg, der 1948 unmittelbar nach der Verabschiedung der Resolution der Vereinten Nationen erfolgte, die die Teilung Palästinas besiegelte) und es gab solche, die kamen unerwartet (wie der Yom-Kippur-Krieg 1973). Es gab Kriege, die waren für einige vorhersehbar, während andere sich konsequent weigerten, die Indikatoren richtig zu deuten - wie etwa in den späten 30er-Jahren des 20. Jahrhunderts, als die Kriegsvorbereitungen Hitlers von der britischen Regierung Eden lange Zeit falsch interpretiert wurden, während Winston Churchill anhand der Ziele Hitlers und der enormen Kriegsanstrengung des Dritten Reiches bereits die richtigen Schlüsse gezogen hatte. ${ }^{21}$

Ab wann muss man aber realiter mit dem Ausbruch von welchen Kriegen rechnen? Was sind die entsprechenden Anhaltspunkte? Dafür gibt es kein umfassendes methodisches Konzept. Man kann natürlich eine Vielzahl von Indikatoren nehmen, die sich quantifizieren lassen und anhand derer man Tendenzen in Richtung der Verschärfung von Konflikten in unterschiedlichen Regionen ablesen kann. ${ }^{22}$ Entsprechende Forschungsergebnisse liegen vor und lassen Rückschlüsse darauf zu, in welchen Regionen mit Destabilisierung zu rechnen ist (was als Voraussetzung für den Ausbruch von Gewalt angesehen wird). Aber daraus lassen sich keine Prognosen darüber ableiten, ob politische Führer sich entscheiden einen Krieg zu beginnen. Alle großen und mittleren Kriege der Geschichte waren solche, bei denen es auf Entscheidungen politischer Führer ankamen. Zwischen der Verschärfung einer sozialen, wirtschaftlichen und politischen Krise und dem Ausbruch eines richtigen Krieges liegen immer noch politische Entwicklungen, bei denen Personen an die Macht gelangen, die einen Krieg aus welchen Gründen auch immer wollen und die in der Lage sind, die dafür benötigten Ressourcen (Menschen und Waffen) zu rekrutieren und zu mobilisieren. Von daher ist es angeraten, doch wieder zu Clausewitz zurückzugehen, der die Wahrscheinlichkeit eines Krieges dann für gegeben hielt, wenn

21 Churchill 1948.

22 Ein derartiges Projekt betreibt das The Hague Center for Strategic Studies mit großem Erfolg; vgl. https://www.hcss.nl/products-andservices/. In den USA gibt es seit den 90er Jahren ein staatlich finanziertes wissenschaftliches Projekt, welches anhand von quantitativen Indikatoren Prognosen über die Wahrscheinlichkeit von krisenhaften Zuspitzungen liefern solle (Political Instability Task Force - PITF). Dieses wurde bis 2012 von der George Mason University im Bundesstaat Virginia geleitet. Zur Methodik dieses Projektes vgl. Goldstone/ Bates/Epstein/Gurr/Lustik/Marshall/Ulfelder/Woodward 2010. Das Projekt wird heute im begrenzten Umfang durch das Center for Systemic Peace weitergeführt. 
zwei Dinge zusammentreffen: „die Größe der vorhandenen Mittel und die Stärke der Willenskraft. “23

Selbst wenn man einen Krieg einigermaßen verlässlich voraussagt, bedeutet dies nicht, dass man auch den Verlauf des Krieges einschätzen oder gar vorhersagen kann. ${ }^{24}$ Allerdings sind die Fortschritte bemerkenswert, die im Bereich der Analyse von Streitkräftepotenzialen, Doktrinen und der wirtschaftlichen Unterstützungskapazitäten gemacht worden sind. Schon lange vor dem Ausbruch des Ersten Weltkriegs vermochten so unterschiedliche Charaktere wie General-Feldmarschall Helmuth Moltke (der Ältere) und Friedrich Engels die Folgen eines großen Krieges (eines „Volkskrieges“, wie Moltke es ausdrückte) in Europa auszumalen. ${ }^{25}$ Sie kamen zu der ernüchternden Feststellung, wonach diese Kriege in großen Verlusten an Mensch und Material enden würden, ohne dass erkennbare Entscheidungen fielen. Die beste Analyse legte 1898 der russisch-polnische Industrielle und Bahnunternehmer Ivan Bloch vor. In einer sechsbändigen Untersuchung von fast 3.500 Seiten setzte er sich detailliert mit dem Stand der Waffentechnik und der industriellen Unterstützung für Kriege in modernen Industriestaaten auseinander. ${ }^{26}$

Bloch kam zu dem Ergebnis, dass jeder künftige große Krieg in Form von riesigen Materialschlachten ablaufen werde, die wenig territoriale Veränderungen bewirken würden. Diese Anstrengungen würden jeden Staat auf Dauer überfordern und zudem soziale Unruhen und Revolutionen befördern. Er sagte voraus, dass ein künftiger Großkrieg in Europa zwischen 4 und 6 Jahren dauern werde und am Ende alle Parteien erschöpft und destabilisiert seien. Dies war geradezu eine Voraussage des Verlaufes des Ersten Weltkrieges. Bloch ließ das Buch in russischer, deutscher, englischer und französischer Sprache erscheinen und hoffte, dadurch die Politik davon überzeugen zu können, dass sich Krieg nicht mehr lohne. Leider wurden seine Forderungen in der Politik nicht aufgegrif-

23 Clausewitz 1867, 7 (Erster Band, erster Teil).

24 Das ist schon seit der Antike bekannt, als der Sage nach das Orakel von Delphi dem lydischen König Krösus prophezeite, dass, wenn dieser das Perserreich angreife, ein großes Reich zerstört werde - am Ende war es das Reich des Krösus, welches zerstört war.

25 Vgl. Helmuth von Moltkes letzte Rede im Reichstag vom 14.5.1880, in: Stenographische Berichte über die Verhandlungen des Reichstags, 1890-91, Band 114, Berlin 1892, S. 76-77; aber auch seine Geschichte des deutsch-französischen Krieges begann mit einem düsteren Ausblick auf die kommenden Kriege, in denen er voraussah, dass sich ganze Völker gegenseitig bekriegen werden mit allen ihnen verfügbaren Ressourcen, vgl. Moltke 1891, 1-2; siehe auch Engels 1888. 26 Bloch 1898.

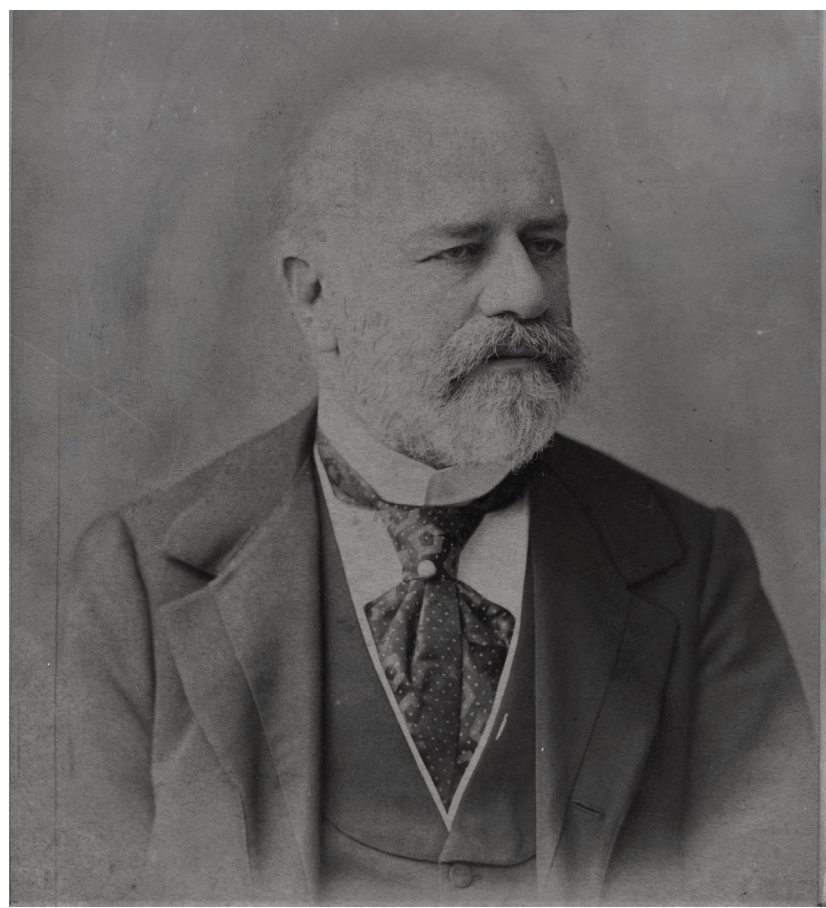

Ivan Bloch

fen, ${ }^{27}$ wenngleich unter Militärs ähnliche Einschätzungen über die Führbarkeit von Kriegen in Europa herrschten. ${ }^{28}$ Unter den Militärs Europas bedeutete diese Einschätzung aber nicht, dass der Politik empfohlen wurde, von Kriegen abzusehen. Vielmehr war es der Ehrgeiz hoher Militärs, trotz widriger Bedingungen Möglichkeiten zu finden, wie entscheidende Siege errungen werden konnten. Dies war besonders im preußischen und später im deutschen Generalstab zu finden. ${ }^{29}$ Aber die Armeen anderer europäischer Staaten (insbesondere in Frankreich und Russland) dachten in ähnlicher Weise, was bedeutete, dass Schnelligkeit und Entschlussfreudigkeit, Überraschung, aber auch die Moral der Truppe sowie die Bereitschaft, enorme Mengen an Material einzusetzen und Tausende von Soldaten zu opfern, zunahmen..$^{30}$ Damit bedienten sie die Interessen der meisten europäischen Politiker, für die Vorstellungen von Mäßigung und Bona-fide-Verhandlungen und von Kompromissen fremdartig waren, die andererseits aber auch kein großes Interesse daran hatten, sich in die Details und Dilemmata militärischer Strategien hineinzudenken.

\section{Sapper 2008.}

28 Förster 1987, Förster 1995, Förster 1999.

29 Vgl. Rothenberg 1986, Wallach 1967.

30 Vgl. Burchardt 1968; Storz 1992, 372; Howard 1986, Snyder 1984. 
In den Zwischenkriegsjahren änderte sich an der Unverbundenheit militärischen und politischen Denkens im Prinzip nichts, allerdings unter anderen Vorzeichen. Unter dem Eindruck der menschlichen und wirtschaftlichen Katastrophe des Ersten Weltkriegs gingen vor allem Frankreich, Großbritannien und die USA (sowie auch die Weimarer Republik) den Weg der Vermeidung von Kriegen und beschränkten sich in militärischen Vorbereitungen primär auf defensive Ansätze. In dieser Zeit entwickelte sich jedoch das kreative taktische und operative Denken in eine Richtung, in der aufgrund der Mechanisierung der Landkriegsführung und des Zusammenwirkens mit der weiter fortgeschrittenen Luftkriegsführung Optionen der raschen und erfolgreichen Offensive möglich wurden die sogenannte Blitzkrieg-Strategie. Derartige Überlegungen wurden in den 20er- und 30er-Jahren in westlichen Staaten zwar angestellt, fanden dort aber wenig politische Unterstützung. ${ }^{31}$ Im nationalsozialistischen Deutschland und in der Sowjetunion (bis zur Liquidierung des Generalstabschefs Tuchatschewski im Jahr 1937) wurden diese Ideen aber dankbar aufgenommen und im Sinne der Unterordnung des militärstrategischen Denkens unter die Maximen der Parteien (NSDAP, KPdSU) in die operativen Planungen integriert. Blitzkrieg-Strategie bedeutete eine eher indirekte Strategie, mit der die Materialschlachten des Ersten Weltkriegs vermieden und rasche Siege durch kühne Umfassungsaktionen mechanisierter Verbände möglich werden sollten, die dabei von der Luftwaffe unterstützt wurden. ${ }^{32}$ Sie baute auf Überraschung und Verwirrung in der gegnerischen Tiefe und der damit verbundenen Psychologie auf. Sie war erfolgreich in den ersten Jahren des Krieges und wurde, nachdem sie von den Gegnern des Dritten Reichs verstanden und auch adaptiert worden war, immer weniger wirkungsvoll, sodass die meisten Schlachten des Zweiten Weltkrieges erneut Materialschlachten waren, bei denen diejenige Seite erfolgreich blieb, die den größeren Materialansatz aufweisen konnte. Die großen Anfangserfolge Hitlers hätten vermieden werden können, wenn das revolutionäre Potenzial der neuen Waffensysteme (Panzer, gepanzerte Fahrzeuge, Flugzeuge zur taktischen Unterstützung und zur Bekämpfung strategischer Ziele, verbesserte Kommunikationsmöglichkeiten) von westlichen Militärs und Politikern rechtzeitig erkannt und in ihren Planungen berücksichtigt worden wäre. Die ent-

31 Vgl. Fuller 1923, Liddell Hart 1927, Fuller 1928, Liddell Hart 1937. Siehe auch Posen 1984.

32 Michael Geyer hat die Blitzkriegstrategie als eine "countercommand rather than a counterforce" Strategie bezeichnet (Geyer 1986, 585), Liddell Hart charakterisierte sie als indirekte Strategie (Liddel Hart 1991, 207-237). sprechenden Anregungen von Experten gab es, sie passten aber weder in die politische Landschaft noch in die Denkweisen der Politik und des Militärs. ${ }^{33}$ Diese Entwicklungen zeigen, dass der Verlauf von Kriegen vorhersagbar sein kann, aber dass es nicht gesichert ist, dass die entsprechenden Botschaften in der Politik und bei der Generalität ankommen bzw. gewürdigt werden.

Erst nach dem Zweiten Weltkrieg (und gefördert durch das Aufkommen von Kernwaffen) wurde vor allem in den USA Analysen Aufmerksamkeit geschenkt, die sich mit der Frage beschäftigten, wie in der Zukunft Kriege ablaufen würden. Hier sind in erster Linie die bahnbrechenden Arbeiten von Bernard Brodie, Albert Wohlstetter, Thomas Schelling, Henry Kissinger und Hermann Kahn zu nennen, die sich mit den möglichen Verläufen von Kriegen befassten, in denen Kernwaffen zum Einsatz kamen. ${ }^{34}$ Aber auch die Veränderungen im Bereich der Marinestrategie, der kombinierten Luft- und Bodenoperationen unter Bedingungen der Digitalisierung sowie der Bekämpfung von irregulären Guerilla-Verbänden wurden nicht nur in militärischen Stäben behandelt, sondern waren Gegenstand akademischer Analysen, die auch in die Beratung von Politik und Militär einflossen. ${ }^{35}$ Damit hatte sich erstmals etwas Neues entwickelt: Wissenschaftler hatten die Möglichkeit, strategische und operative Fragen nicht nur vertieft zu behandeln, sie wurden auch in der Politik und von den Institutionen des Militärs (in den USA das Department of Defense) ernst genommen und ihr Rat war gefragt. Die sich daraus entwickelnde strategische community innerhalb der Staaten der westlichen Welt ist bis heute ein wesentliches Element einer Politik, die versucht, Fragen von Krieg und Frieden mit größerer Offenheit für die damit verbundene Komplexität zu behandeln und diese Debatte auch in Parlamente und in die Öffentlichkeit zu tragen.

Eine derartige Debatte ist notwendig, will man zwei Defizite vermeiden, die möglicherweise entscheidend sein können für die Frage, ob ein größerer Krieg ausbricht: Das eine Defizit ist die Falle des Patriotismus, das andere die des Pazifismus. Die Patriotismus-Falle besagt, dass Politik derart durch patriotische Impulse gesteuert sein kann, dass Entscheidungsträger den Sinn für die Risiken verlieren, die mit dem Einsatz von militärischer Gewalt verbunden sind, so wie es 1914 der Fall war. Im Hintergrund steht dabei oft die Instrumentalisierung von Patriotismus und Kriegsbegeisterung. Mit ihr soll von innenpolitischen Legitimitätsdefiziten abgelenkt werden, insbesondere

33 Fuller 1961, 239-247, siehe auch Reid 2008.

34 Krause 2001, ausführlicher Freedmann 2003.

35 Näheres siehe Krause 2015a, 91 f; sowie Krause 2017. 
unter Bedingungen extremer sozialer Ungleichheit. Die Pazifismus-Falle besagt, dass die Angst vor dem Gebrauch von militärischer Gewalt (oder auch nur deren Androhung zum Zweck der Abschreckung) so groß ist, dass man reale Bedrohungen nicht zu erkennen vermag und damit Kriege wieder möglich werden (so wie die Beschwichtigungspolitik Großbritanniens in den Jahren vor dem Zweiten Weltkrieg). ${ }^{36}$

Allerdings sollte bei aller Begeisterung über die wichtige Rolle, die Wissenschaft heute im Vergleich zur Zeit vor dem Ersten Weltkrieg bei der Erörterung strategischer Fragen einnimmt, eines nicht übersehen werden: Es gibt in der Wissenschaft (wie soll es anders sein?) unterschiedliche Denkschulen und daher gibt es auch nicht immer eindeutige Antworten aus der Wissenschaft. Ganz plakativ betrachtet kann man die wissenschaftliche Debatte zur Wahrscheinlichkeit von Kriegen in Optimisten und Pessimisten trennen.

Die Optimisten, wie der französische Strategieexperte Bruno Tertrais, gehen davon aus, dass sich große und kleine Kriege, wie wir sie aus der europäischen Geschichte kennen, nicht mehr wiederholen werden. Tertrais argumentiert, dass wir uns einem Punkt in der Geschichte näherten, an dem man sagen könne, dass der Krieg, von dem es lange geheißen habe, er sei ein unvermeidlicher Teil der Geschichte, nicht mehr stattfinde. ${ }^{37}$ Tertrais beruft sich auf eine Reihe von Autoren, die aufzeigen, dass sich vor allem nach dem Zweiten Weltkrieg kein großer Krieg mehr ereignet habe, dass sich eine internationale Gesellschaft herausgebildet habe, die sich stark auf die Beachtung von Normen und Prinzipien abstütze, und dass die Bedeutung des internationalen Handels zugenommen habe. Die Kräfte, die 1914 und 1939 auf Krieg gedrängt hätten, seien heute in der Politik nicht mehr präsent. Die Botschaft zweier Weltkriege und der mäßigende Einfluss von Kernwaffen führten dazu, dass es heute immer weniger Kriege gebe und diese sich vornehmlich an den Randzonen der Politik abspielten.

Die Pessimisten sehen das ganz anders. Der amerikanische Strategieexperte Robert Kagan etwa geht auch davon aus, dass die letzten 75 Jahre die friedlichsten der Weltgeschichte gewesen seien. Daraus dürfe man aber keine aufsteigende Linie in Richtung Zivilisierung der internationalen Politik ableiten. Tatsächlich sei die friedvolle Periode Folge des Engagements der USA für eine

36 Schon Clausewitz schrieb vor knapp 200 Jahren: „... in so gefährlichen Dingen, wie der Krieg eines ist, sind die größten Irrtümer, welche aus Gutmüthigkeit entstehen, gerade die schlimmsten." Clausewitz 1867, 7.

37 Tertrais 2012, 7, noch deutlicher Mousseau 2019.

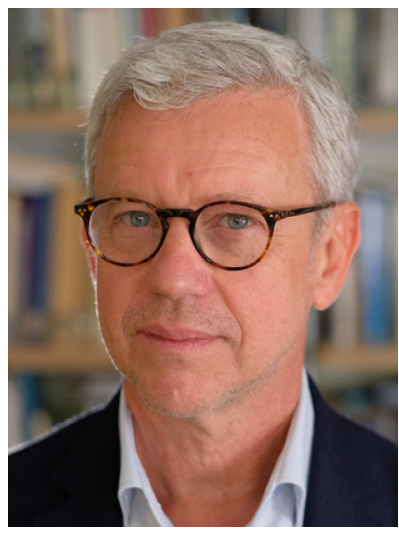

Bruno Tertrais

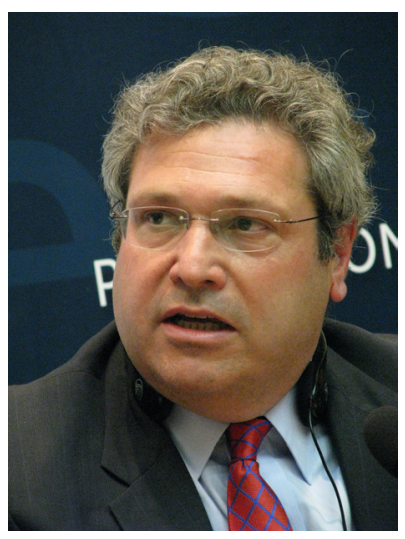

Robert Kagan liberale internationale Ordnung gewesen. Diese Ordnung habe $\mathrm{zu}$ dem qualitativen Wandel der internationalen Beziehungen beigetragen. Sie sei mit dem Aufstieg Chinas als globaler peer-competitor der USA sowie dem Wiederauftreten Russlands und des Irans als Herausforderer in Gefahr, nicht zuletzt, weil das Bewusstsein innerhalb der USA dafür abnehme, wie sehr die Garantie der internationalen Ordnung durch die USA in deren ureigenem Interesse liege. Ohne diese Ordnung würden die internationalen Beziehungen erneut durch Anarchie und das Gesetz des Dschungels strukturiert und mehr Kriege seien die unabweisbare Folge. ${ }^{38}$ Andere Pessimisten setzen die Akzente teilweise anders, aber in der Regel überwiegt die Einschätzung, dass mit dem Aufstieg Chinas, der Relativierung des Einflusses der USA und der Erosion der liberalen internationalen Ordnung die Kriegsgefahr ansteige. ${ }^{39}$

Es fällt schwer, entweder der einen oder der anderen Perspektive den Vorzug zu geben. Vor allem ist zu bezweifeln, ob man die Argumentation in dieser Allgemeinheit führen kann. Vielmehr scheint es sinnvoll zu sein, einzelne mögliche Kriegsschauplätze daraufhin zu untersuchen, ob die optimistische oder die pessimistische Variante zutreffen bzw. was noch an Handlungsoptionen europäischer, deutscher oder westlicher Politik besteht, um Kriege zu verhindern, die anderenfalls drohten. Dabei wird im Folgenden das Hauptaugenmerk auf große Kriege gelegt.

38 Kagan 2018, ähnlich argumentieren Daalder/Lindsay 2018 sowie Mandelbaum 2019; zum Thema internationale Ordnung vgl. Menzel 2015, sowie Ikenberry 2001, Ikenberry 2011.

39 Z. B. Allison 2017, siehe auch Mearsheimer 2010, Mearsheimer/ Walt 2016, Mearsheimer 2019. 


\section{Kriegsrisiken und Gefahren in der heutigen internationalen Politik}

Im Folgenden sollen einige der am ehesten zu vermuteten großen Kriegsszenarien behandelt werden. Dazu gehören (1) die Gefahr eines allgemeinen nuklearen Krieges, (2) Kriege, die von revisionistischen Großmächten im Besitz von Kernwaffen gegen Nicht-Kernwaffenstaaten geführt werden, (3) die Kriegsgefahr auf der koreanischen Halbinsel, (4) die Wahrscheinlichkeit eines Krieges zwischen Indien und Pakistan, (5) die Gefahr von Kriegen im Nahen Osten, und (6) die Risiken sonstiger Kriege.

\subsection{Die Gefahr eines allgemeinen nuklearen Krieges}

Als der damalige Direktor des Institute for Strategic Studies, Alastair Buchan, Ende der 60er-Jahre über Kriegsrisiken schrieb, stand für ihn die Gefahr eines allgemeinen Kernwaffenkrieges zwischen den USA und der Sowjetunion im Vordergrund. ${ }^{40} \mathrm{Zu}$ dem Zeitpunkt hatten beide Mächte enorme Bestände an Kernwaffen angehäuft, von denen ein Großteil interkontinentale Reichweiten besaß. Beide Staaten waren in der Lage, sich gegenseitig mehrfach auszulöschen und die gesamte Welt in einen nuklearen Holocaust hineinzuziehen. Die nuklearstrategischen Arsenale waren Teil einer weltumspannenden Konfrontation zwischen NATO und Warschauer Pakt und hingen eng mit einem möglichen umfangreichen Kriegsschauplatz in Europa zusammen, an dem von Anfang an mehr als 2 Millionen Soldaten teilgenommen hätten. Buchan zitierte verschiedene Szenarien, unter denen diese Waffen auch dann eingesetzt werden könnten, wenn es gar nicht beabsichtigt worden wäre. Hierzu gehörte der Krieg aus technischem Versehen oder aufgrund menschlichen Versagens. Heute, mehr als 50 Jahre nach Buchans Analyse und nach dem Ende des Ost-West-Konflikts, besteht die nuklearstrategische Konkurrenz zwischen den USA und Russland weiter, aber sie steht nicht mehr im Mittelpunkt der Sorgen. Zum einen ist diese Konkurrenz infolge der Abrüstungsverträge (START, New START) deutlich geschrumpft, zum anderen ist heute nicht vorstellbar, aus welchem Grund Russland oder die USA versuchen sollten, gegeneinander einen selbstmörderischen Kernwaffenkrieg zu führen. Ein nicht provozierter Nuklearschlag würde eine ähnlich geartete

40 Buchan 1968, 162-195.
Vergeltung zur Folge haben, weil keine Seite die Möglichkeit hat, die andere nuklear zu entwaffnen. Von daher hat sich eine gewisse Stabilität eingestellt, die gemeinhin auch als gegenseitig gesicherte Zerstörungsfähigkeit (mutual[ly] assured destructiveness - MAD) bezeichnet wird. Diese ist paradoxerweise umso stabiler, je mehr Kernwaffen es auf beiden Seiten gibt.

Natürlich besteht die Gefahr eines Kernwaffenkrieges aus Versehen. Diese Gefahr ist seit den 50er-Jahren des 20. Jahrhunderts bekannt und ist in einer Reihe von Studien und Untersuchungen behandelt worden. ${ }^{41}$ Heute dürfte es sich um eine eher theoretische Gefahr handeln, wenngleich es technologische Entwicklungen gibt, die immer wieder die Möglichkeit für radikale Schritte eröffnen könnten. ${ }^{42}$ Aber entscheidend ist, dass Staaten wie die USA und Russland nach Jahrzehnten nuklearer Gegnerschaft, Konkurrenz und teilweise Kooperation ein erhebliches Maß an Mäßigung entwickelt haben und sich an gewisse Spielregeln halten. ${ }^{43}$ Im Mittelpunkt der Furcht steht meistens eine falsche Information aus dem Bereich der Frühsensoren über einen angeblichen allgemeinen Kernwaffenangriff. Heute wird jede Information von Frühwarnsensoren sehr genau daraufhin überprüft, ob sie tatsächlich die Realität widerspiegelt. Weder im Kreml noch im Weißen Haus sitzen Personen, die auch nur annähernd willens sind, die Welt mit einem umfassenden Nuklearwaffenangriff in die Katastrophe zu treiben. Das war zu Zeiten des Kalten Krieges allerdings auch nicht grundsätzlich anders, wie inzwischen aus dem Bericht des früheren Obersten der Sowjetarmee, Stanislav J. Petrov, erkennbar geworden ist. Dieser war in den 90er-Jahren an die Öffentlichkeit getreten und hatte berichtet, dass er als Mitglied einer Einheit der Roten Armee, bei der Informationen der Frühwarnsysteme eingingen, im Jahr 1983 Informationen über angreifende amerikanische Interkontinentalraketen nicht weitergegeben habe, weil sie ihm nicht als glaubhaft erschienen seien. Petrov wurde in den Medien fälschlicherweise als derjenige gefeiert, der 1983 im Alleingang und ohne Wissen seiner Vorgesetzen den Ausbruch eines Atomkriegs verhindert habe. ${ }^{44}$ Tatsächlich

41 Vgl. Iklé 1958, Blair 1985, Blair 1987, Blair 1993, Bracken 1983, Carter 1987a, Carter 1987b, Posen 1991, Sagan 1985, Sagan 1993, Thayer 1994, Toomay 1987, Zraket 1984, einen Überblick aus heutiger Sicht gibt Diniz 2016; zur generellen Problematik mit Blick auf die anderen Kernwaffenstaaten siehe Shaheen 2019.

42 Vgl. Acton 2020 sowie Chyba 2020.

43 Tannenwald 2020.

44 z. B. Der Mann, der den Dritten Weltkrieg verhinderte, Spiegel Online vom 22.4.2010; Ronald Gerste: Haarscharf an einem Atomkrieg vorbei, Neue Zürcher Zeitung vom 25.9.2013; Ursula Scheer: Wie ein 
hat er nur das getan, was seinerzeit seine Aufgabe war: $\mathrm{zu}$ prüfen, ob ein aufgrund einzelner Informationen gemeldeter Angriff der anderen Seite nicht auf technischem Versehen beruhte. Dies sind Standardprozeduren sowohl in den USA als auch in der Sowjetunion bzw. heute in Russland, und es wird mehr derartige Szenen gegeben haben. ${ }^{45} \mathrm{Zwar}$ seien dem mittlerweile verstorbenen Petrov die Ehrungen gegönnt, die er erhalten hat, aber er war keinesfalls der Einzelkämpfer gegen das Establishment, als der er immer wieder dargestellt wird.

Das Szenario eines allgemeinen Kernwaffenkrieges aufgrund falscher Informationen oder technischer Fehler behält nur dann seine Berechtigung, wenn sowohl die USA als auch Russland ihre Arsenale ständig unter der Bedingung aktiv halten, dass diese auch bei einem kurz bevorstehenden Angriff gestartet werden können (Launch-on-warning-Doktrin). ${ }^{46}$ Die USA haben diese Doktrin 1997 bereits aufgegeben und würden einen Nuklearangriff Russlands aussitzen, bevor sie zurückschlagen. ${ }^{47}$ Russland hält noch an der Launch-on-warning-Doktrin fest, was selbst unter russischen Experten kritisiert wird. ${ }^{48}$ Wenn es - auch für deutsche Politiker - etwas zu unternehmen gibt, dass man diese Gefahr weiter minimieren könnte, dann wäre es, auf Russland Druck auszuüben, diese Doktrin abzuschaffen. ${ }^{49}$

Ein weiteres Element der Unsicherheit bezüglich der nuklearstrategischen Balance zwischen Russland und den USA ist die Tatsache, dass die VR China ihre nuklearen Fähigkeiten ausbaut und zunehmend Raketen mit mittlerer und interkontinentaler Reichweite beschafft. China verfügt weiterhin über weniger Kernwaffen als Russland oder die USA (etwa 300), es baut aber seine Fähigkeiten aus. So hat es in den vergangenen Jahren eine neue mobile Mittelstreckenrakete beschafft und eine verbesserte, mobile Abschussrampe für Interkontinentalraketen in Dienst gestellt. Weiter arbeitet China an Mehrfachsprengköpfen für Interkontinentalraketen und an einer luftgestützten ballistischen Rakete, die konventionell und nuklear bestückt werden kann. ${ }^{50}$ Bemerkenswert ist auch

russischer Oberst den Atomkrieg verhinderte, Frankfurter Allgemeine Zeitung vom 4.8.2015.

45 Sagan spricht von zwei ernsthaften derartigen Vorfällen, die sich in den USA bis 1990 ereignet hätten, vgl. Sagan 1991, 17.

46 Vgl. Steinbruner 1984.

47 https://www.armscontrol.org/act/1997-11/news/clinton-issuesnew-guidelines-us-nuclear-weapons-doctrine.

48 Dvorkin 2019, 265.

$49 \mathrm{Zu}$ weiteren Vorstellungen zur Reduzierung der Risiken versehentlicher Atomkriege vgl. Van der Meer 2018.

50 Kristensen/Korda 2019. die Erweiterung des Arsenals an Interkontinentalraketen, die von nukleargetriebenen U-Booten abgeschossen werden können. China verfügt mittlerweile über 4 U-Boote der Jin-Klasse (Typ 094), die jeweils 12 JL-2 (CH-SS-N-14)Raketen auf eine Distanz von etwa 7,400 km abfeuern können. ${ }^{51}$ Die Zahl der Jin-Klasse-U-Boote soll auf 8 ansteigen..$^{22}$

Wie sich die nuklear-strategische Triade zwischen den USA, Russland und China in den kommenden Jahren entwickelt, ist offen. Die entstehende Trilateralität ist Anlass für viele Beobachter, zu fürchten, dass die bestehenden Systeme der Kooperation komplizierter werden..$^{53}$ Es sind in diesem Zusammenhang unterschiedliche Szenarien vorstellbar, beginnend von einem nuklearstrategischen Rüstungswettlauf zwischen den USA und China bis hin $\mathrm{zu}$ einer Beziehung zwischen Washington und Beijing, bei der beide Seiten versuchen, die Konkurrenz flach zu halten. Dies könnte etwa so aussehen, dass die VR China nicht versucht, die gleichen Quantitäten und Qualitäten an Kernwaffen zu erwerben wie Russland und die USA, andererseits aber seine gesicherte Zweitschlagskapazität gegenüber den USA ausbaut. ${ }^{54}$ Manches deutet darauf hin, dass sich die Dinge in letztgenannte Richtung entwickeln, denn weder die Regierung in Washington noch die in Beijing haben ein Interesse an einer Wiederholung des nuklearen Rüstungswettlaufs der 60er-, 70er- und 80er-Jahre des 20. Jahrhunderts.

Letzteres weist auf etwas ganz Anderes hin, das im folgenden Abschnitt thematisiert werden soll: Kernwaffenstaaten (zumindest solche mit Großmachtambitionen) nutzen Kernwaffen weniger, um die anderen Kernwaffenmächte auszuschalten (was ohnehin kaum realistisch ist und wo bei allen Akteuren auch nicht der entsprechende politische Wille im Sinne Clausewitz' zu erkennen ist), sondern vielmehr, um sich ein Sanktuarium zu schaffen, von dem aus Nachbarstaaten oder andere, entferntere Staaten bedroht werden können, die sich nicht dem Willen der Nuklearmacht unterwerfen wollen. Nach außen wird gerne die Behauptung aufrechterhalten, es gehe - etwa im Fall Russlands - lediglich um den Erhalt des Großmachtstatus und um das eigene Überleben, ${ }^{55}$ tatsächlich entwickeln Großmächte wie Russland und China subtile Formen der konfrontativen Politik gegenüber Nachbarn, die Konsequenzen auch für die Beziehungen zu den USA

\footnotetext{
51 IISS 2020, 259.

52 Richard D. Fisher, Jr: China advances sea- and land-based nuclear deterrent capabilities. Jane's Defence Weekly, 16.12.2015.

53 Miller 2020, Dvorkin 2019, Krause 2015b.

54 Roberts 2016, 160.

55 So etwa bei Loukianova Fink/Oliker 2020.
} 
und den gesamten Westen haben. Iran tendiert mit seinem Kernwaffenprogramm in die gleiche Richtung. Es geht um die Fortsetzung von Konkurrenz unter Bedingungen gegenseitig gesicherter Abschreckung und der damit verbundenen Abneigung aller Beteiligten, in die nuklearstrategische Ebene einzusteigen. ${ }^{56}$

\subsection{Kriegsgefahr durch Übergriffe nuklearer Großmächte gegen Nichtkernwaffenstaaten}

Die Gefahr von begrenzten oder regionalen Kriegen, die von Kernwaffenstaaten ausgehen, die anderen Staaten ihren Willen aufzwingen oder sich Territorien aneignen wollen, stellt heute absehbar die größte Ursache von Kriegen dar. Dieser Trend hat sich in den letzten Jahren deutlich verstärkt. Er ist symptomatisch für den Verfall der bestehenden liberalen internationalen Ordnung. In erster Linie stehen hier Russland und China im Mittelpunkt. China, Russland (und auch der Iran) sind Mächte mit revisionistischen Zielen, d.h. sie wollen die bestehende internationale Ordnung abschaffen oder in ihrem Sinne verändern. Anlass dazu bieten häufig Konfliktsituationen in der unmittelbaren Nachbarschaft.

Was Russland und China betrifft, so gibt es Ähnlichkeiten und Unterschiede im Vorgehen. Beiden ist gemein, dass sie die liberale internationale Ordnung ablehnen, weil diese in ihrer Sichtweise eine Ordnung unter amerikanischer Hegemonie ist. Sie streben Einflusszonen in ihrer Nachbarschaft an, die mit unterschiedlichen Instrumenten verfolgt werden. Beim Blick auf die Instrumente wird allerdings auch die Verschiedenartigkeit der russischen und der chinesischen Interessen erkennbar.

$\mathrm{Zu}$ diesen Instrumenten gehört auf Seiten Russlands der Aufbau von Abhängigkeiten im Bereich der Energieversorgung. Dazu gehört auch die Hilfe bei der innenpolitischen Stabilisierung autoritärer und kleptokratischer Staaten (wie in fast allen früheren Teilrepubliken der ehemaligen Sowjetunion). Die Schaffung von Abhängigkeit von russischer Militärhilfe ist hier ebenfalls zu erwähnen. Dies gilt besonders für Staaten, die sich außenpolitisch übernehmen (z.B. Armenien), oder für staatsähnliche territoriale Selbstvertretungskörperschaften, die sich auf ansonsten aussichtslose Sezessionsabenteuer eingelassen haben (wie Abchasien, Süd-Ossetien, Transnistrien). Seit 2008 - dem Krieg Russlands gegen Georgien - und erst

56 Bergeron 2018, De Wijk 2018, Roberts 2020. recht seit 2014 - Annexion der Krim und Versuch der Destabilisierung der Ukraine durch die gewaltsame Übernahme der Staatsgewalt in russischsprachigen Gebieten durch „Aufständische“ - ist Russland dazu übergegangen, mit Instrumenten der hybriden Aggression und im Fall der östlichen Ukraine auch durch den direkten Einsatz regulärer Militäreinheiten (und mehr und mehr privater, d.h. irregulärer Einheiten) seine Interessen durchzusetzen. Diese Entwicklung ist durch ein vorsichtiges Herantasten in Richtung einer immer weiter fortschreitenden Eskalation gekennzeichnet gewesen. Im Fall der Ukraine bereitete sich Russland mindestens zwei Mal auf eine vollständige Invasion des Landes vor, nur um diese dann doch wieder abzubrechen. Das alles kann Russland risikofrei unternehmen, weil im Hintergrund seine Kernwaffen stehen.

Ziel der Kriegsführung gegen Georgien und gegen die Ukraine ist die Bestrafung von deren Wunsch nach Integration in die westlichen Institutionen, d.h. in die Europäische Union und in die NATO, und deren Hinwendung zu demokratischen Regierungsformen. Dadurch, dass diese Länder destabilisiert werden, sollen sie dazu gezwungen werden sich den russischen Sicherheitsinteressen unterzuordnen. Die Tatsache, dass sowohl EU wie auch NATO von Beitrittskandidaten erwarten, dass diese keine ungelösten Territorialprobleme mit Nachbarstaaten haben, macht es der russischen Politik leicht. Man kann auch sagen, sie fordert geradezu dieses Verhalten heraus. Als Konsequenz dieser russischen Kriegsführung (hybride Aggressionen, begrenzte Kriege, bei denen lokale Abenteurer und Kriminelle ebenso zum Einsatz kommen wie private Milizen) hat Russland es geschafft, Staaten wie die Ukraine und Georgien zu destabilisieren, Territorien von über 70.000 qkm unter seine Kontrolle zu bringen und damit andere Kandidaten von ähnlichen Versuchen der Anbindung an westliche Institutionen abzuhalten (Belarus, aber auch Aserbaidschan sowie die zentralasiatischen Staaten).

In den vergangenen Jahren, spätestens seit 2013, trat jedoch eine weitere Kriegsgefahr in den Vordergrund: die Bedrohung des Baltikums durch eine russische Invasion. Hier ist der Einsatz von ganz anderer Art, denn diese Länder sind Mitgliedstaaten der NATO. Vor allem die Militärübungen Zapad 2013 und Zapad 2017, die im Westen Russlands geführt wurden und an denen zwischen 70.000 und 100.000 Soldaten sowie andere Angehörige russischer Sicherheitsministerien teilnahmen, wurden von Beobachtern als Probe für den Ernstfall interpretiert. Erst wurde ein fiktives Land von der Größe der drei baltischen Staaten von Rebellen erobert, dem folgte die Verteidigung des fiktiven Landes gegen eine reguläre Invasion eines mit modernsten Waffen ausgerüsteten Gegners, an deren Ende 
(zumindest galt das für Zapad 2013) auch der Einsatz von taktischen Kernwaffen stand. ${ }^{57}$

Beide Übungen zeigten auf, wie schnell Russland (im Verbund mit Belarus) in der Lage ist substanzielle Truppen in die Gebiete östlich der baltischen Staaten zu verlegen und wie sehr die Modernisierung der russischen Streitkräfte deren Fähigkeit zur Invasion verbessert hat. Die NATO hat auf diese Entwicklung ab 2014 reagiert und eine schnell verlegbare Einsatztruppe (VRJTF) aufgebaut, die im Fall einer Krise in die baltischen Staaten verlegt werden kann und den Einsatz einer größeren NATOTruppe vorbereiten soll. Außerdem stationieren die USA, Großbritannien, Deutschland und andere NATO-Staaten kleinere Einheiten (verstärkte Bataillone, im Fall der USA eine Brigade) in den drei baltischen Staaten sowie in Nordost-Polen. Der Aufbau weiterer Landstreitkräfte, bei dem auch Deutschland eine führende Rolle übernehmen will, ist beschlossen..$^{58}$

Mittlerweile passt auch der Bruch des INF-Vertrages durch Russland in dieses Bild. Die Beschaffung von Mittelstreckenraketen unterschiedlicher Provenienz (im Rahmen und unter Bruch des INF-Vertrags) und deren Stationierung in den westlichen Teilen Russlands sowie auf Schiffen und U-Booten im Nordmeer sowie im westlichen Nordatlantik lässt erkennen, dass Russland sehr konkret in Konzepten eines regionalen Krieges im Ostseeraum (aber auch im Schwarzmeergebiet) denkt, die nur von Moskau initiiert sein können und die gemäß der russischen Militärdoktrin von 2014 auch gewonnen werden müssen. $\mathrm{Zu}$ diesem Zweck beschafft sich Russland derzeit die Fähigkeit zur Eskalationsdominanz (konventionell und nuklear), um einen derartigen Krieg zu den eigenen Bedingungen beenden zu können. Das Szenario bestünde dann darin, dass Russland durch eine überraschende und schnelle Besetzung der baltischen Staaten ein fait accompli schaffte und die NATO-Staaten vor die Alternative stellte, den neuen Status zu akzeptieren oder Gegenstand nuklearer Abschreckung zu werden, die auf das Territorium europäischer Staaten begrenzt bliebe. ${ }^{59}$

Die sich hier abzeichnende Kriegsgefahr ist von der Dimension her nicht mit der militärischen Konfrontation des Kalten Kriegs zu vergleichen. Sie ist bedeutend geringer und geografisch begrenzt. Das bedeutet aber nicht, dass die Folgen einer derartigen Invasion (gerade wenn sie erfolgreich ist) nicht weitreichend sein können. Es könnte bedeuten, dass das atlantische Bündnis darüber

$57 \mathrm{Zu}$ den beiden Übungen vgl. Zdanavičius/Czekai 2015 sowie Boulègue 2017.

58 Meyer zum Felde 2018.

59 Vgl. Brauß/Krause 2019 sowie Kroenig 2018. zerbricht - was die europäische Sicherheit in ihren Grundfesten erschüttern und weitere Kriegsgefahren in Europa nach sich ziehen könnte.

Im Gegensatz zu Russland, welches offenkundig an der Zerstörung der westlichen liberalen Ordnung arbeitet, um sich eine kontinentübergreifende Einflusszone und ein Sanktuarium zu schaffen, geht China anders und sehr viel komplexer vor. Die Führung in Beijing hat bislang von der liberalen Handelsordnung - die Teil der liberalen internationalen Ordnung ist -, sehr profitiert und würde diese nicht zerstören wollen. ${ }^{60}$ Aber diese Ordnung ist von westlichen Staaten (insbesondere den USA) geschaffen worden und wird von diesen kontrolliert. Von daher ist es das Ziel Beijings, eigene Elemente einer Freihandelsordnung zu schaffen, die reale Infrastruktur (Häfen, Straßen, Eisenbahnverbindungen, Flughäfen, Verteilungszentren, Produktionsanlagen etc.) ebenso einschließt wie von China kontrollierte internationale Zahlungssysteme und Finanzinstitutionen. Zudem ist China mit der Betonung der Menschen- und Freiheitsrechte dieser Ordnung ebenso wenig einverstanden wie mit der Achtung der Souveränität auch kleiner Staaten. Chinesische Politik wird eher von dem traditionellen, tributären Konzept geleitet, wonach China als das Reich der Mitte umgeben ist von Ländern, die sich an China ausrichten und keine irgendwie gearteten Bündnisse mit raumfremden Mächten eingehen. In europäischen Termini ausgedrückt bedeutet dies, dass China eine globale Macht mit ähnlicher Reichweite wie die USA sein will und dass es - ähnlich wie Russland - eine exklusive Einflusszone konstituieren will, die mindestens Ostasien und Südostasien umfasst, vermutlich aber noch darüber hinausgehen soll (Indischer Ozean, Afrika).

Auch hier entstehen dadurch Kriegsgefahren, weil China als Nuklearmacht glaubt, seine Machtmittel (soft power und auch hard power) dann effektiver einsetzen zu können, wenn im Hintergrund eine nukleare Abschreckungsoption bereitsteht. Man sieht die zunehmende Bereitschaft Chinas zum Einsatz militärischer Machtmittel heute an drei Schauplätzen: (1) an der Annexion weiter Seegebiete im Südchinesischen Meer und dem Versuch auch im Ostchinesischen Meer Seegebiete exklusiv zu kontrollieren, (2) am Aufbau einer militärischen Drohkulisse gegenüber Taiwan und (3) an den Bemühungen, die amerikanische Präsenz zur See, zu Land und auf Stützpunkten unter militärische Bedrohung zu stellen. Vor allem in den beiden letzten Bereichen verstärken die chinesischen Bemühungen die Gefahr des Ausbruchs von Kriegen.

60 Vgl. Johnson 2019, siehe auch Maull 2020, 16. 
In der hiesigen Öffentlichkeit wird am meisten die schleichende Annexion von Seegebieten im Südchinesischen Meer wahrgenommen. Durch die Inbesitznahme von unbewohnten Felsen und Atollen und deren Befestigung durch die Aufschwemmung großer Sandmengen werden diese zu Militärstützpunkten ausgebaut. China verlegt somit seine territorialen Grenzen faktisch in Richtung Süden unter Verletzung aller einschlägigen Normen des Völkerrechts. Dass es dies tut, hat weniger etwas mit Fischereirechten oder der Suche nach Erdöl zu tun als vielmehr damit, dass China die Insel Hainan zum Weltraumbahnhof und vor allem als Hafen für seine strategischen Nuklear-U-Boote nutzt, deren Zahl - wie oben beschrieben - derzeit bedeutend anwächst. Damit werden - wie eine Untersuchung des ISPK zeigt - das Südchinesische Meer ebenso wie die Straße von Taiwan und große Teile des Ostchinesischen Meer zu maritimen Bastionen, in denen China seine strategischen U-Boote ungestört operieren lassen will. ${ }^{61}$ Vergleichbares kennt man von sowjetischen bzw. russischen Bemühungen, Seegebiete im nordeuropäischen Raum zu nuklearstrategischen Bastionen zu machen (Weißes Meer, Barents-See und Teile der Norwegischen See). Der Hintergrund ist, dass, anders als die USA, die wegen ihrer globalen maritimen Überlegenheit weite ozeanische Gebiete für die Passage ihrer strategischen U-Boote nutzen können, Russland und China darauf angewiesen sind, nahe gelegene Meeresgebiete als Operationsgebiete ihrer strategischen U-Bootflotte zu nutzen. Vor diesem Hintergrund ist es eher unwahrscheinlich, dass über die Kontrolle von Seegebieten im Südchinesischen Meer ein Krieg ausbricht. ${ }^{62}$ Eher wahrscheinlich ist dies im Ostchinesischen Meer, wo sich Japan gegen die chinesischen Ansprüche und Anmaßungen zur Wehr setzt. China verfolgt seit mehreren Jahren eine systematische Politik der ständigen Provokationen Japans durch Luftund Seeraumverletzungen im Ostchinesischen Meer, die mittlerweile die Fähigkeiten der japanischen Marine und Luftwaffe $z u$ übersteigen drohen. ${ }^{63}$ Aber auch hier wird man kaum mit einem größeren Krieg rechnen müssen.

Das, was wirklich in einem großen Krieg enden könnte, sind Beijings Versuche, die immer wieder angekündigte Option einer militärischen Invasion Taiwans zu einer militärisch unterfütterten Option werden zu lassen. In den Worten des US-Department of Defense bereitet sich die chinesische Volksbefreiungsarmee darauf vor, Taiwan mit militärischen Mitteln (Luftangriffe etc.) von

61 Kirchberger/O’Keefe 2019.

62 Taylor 2014.

63 Vgl. Burke/Heath/Hornung/Ma/Morris/Chase 2018; siehe auch Grossman/Beauchamp-Mustafaga/Ma/Chase 2018. politischen Schritten abzubringen, die in Richtung einer weiteren Unabhängigkeit weisen könnten, und sie bereite sich auch darauf vor, die Insel Taiwan auf dem Wege einer militärischen Invasion zu erobern und dabei gleichzeitig eine Intervention der USA zugunsten Taiwans zu unterbinden. ${ }^{64}$ Seit Mitte der 90er-Jahre hat die VR China ihr militärisches Bedrohungspotenzial gegenüber Taiwan massiv ausgebaut: zum einen durch die Stationierung Hunderter Kurz- und Mittelstreckenraketen und von Luftverbänden, die in der Lage sind, Ziele auf Taiwan binnen Minuten anzugreifen. Auch die Luftlandefähigkeiten und die Fähigkeiten, das Seegebiet um Taiwan abzuriegeln und unzugänglich für die US Navy zu machen, sind bedeutend ausgebaut worden. Defizite bestehen noch bei Landungsbooten, sodass die meisten Beobachter davon ausgehen, dass eine akute Invasionsgefahr derzeit noch nicht besteht. ${ }^{65}$ Das könnte sich aber innerhalb weniger Jahre ändern. Taiwan ist relativ gut gerüstet gegen eine Invasion, allerdings dürfte ein Konflikt sich zugunsten Chinas neigen, je länger dieser andauert. Er könnte aber auch zu einer militärischen Konfrontation mit den USA und Japan führen. ${ }^{66}$ Wenn es eine Situation in Ostasien gibt, aus der ein großer und lang anhaltender Krieg resultieren könnte, dann ist es der Anspruch Chinas auf Taiwan. Die Insel hat in der 5.000-jährigen Geschichte Chinas gerade einmal 200 Jahre zu China gehört (1683-1895). Sie ist heute eine der wenigen funktionierenden Demokratien Asiens und verfügt über eine leistungsstarke Volkswirtschaft. Der Anspruch Beijings auf Taiwan ist ebenso frivol, als würde Frankreich Algerien zurückverlangen oder Großbritannien ganz Irland.

In diesem Zusammenhang rückt der dritte Bereich der chinesischen Rüstung in den Vordergrund. Aus chinesischer Sicht ist die nicht unwesentliche militärische Präsenz der USA in der Peripherie Chinas ein Anlass der Verärgerung. Die USA haben Truppen in Südkorea und Japan stationiert, sie verfügen über Marine- und Luftstützpunkte in der Region und haben Verteidigungsabkommen unterschiedlichen Verbindlichkeitsgrades mit mehreren Staaten (Japan, Südkorea, Taiwan, Singapur, Australien, Philippinen). Diese Verärgerung ist einerseits nachvollziehbar, andererseits reflektieren die Sicherheitsabkommen die enorme Angst in der Region vor China und die wichtige Rolle, die die USA als Sicherheitsfaktor dort spielen. China will in der Region offensichtlich und

64 U.S. Department of Defense 2019, 70.

65 Dibb 2019, 17.

66 Grant Newsham: War in the Taiwan Strait is not unthinkable. Akin to 1939 Poland invasion by Soviets and Germans, a battle for Taiwan would have global consequences, Asia Times, 15.1.2020. 
vielleicht auch in ganz Asien zur dominierenden Macht werden und ist fest entschlossen, die dafür notwendigen Mittel aufzubringen. ${ }^{67}$

Im Kern geht es hier um das, was westliche Beobachter anti-access/area denial (A2/AD) nennen und was die Chinesen als active strategic counterattack on exterior lines (ASCEL) bezeichnen. ${ }^{68}$ In beiden Begrifflichkeiten geht es um die Versuche Chinas, amerikanische Militäroperationen in der Nähe von China unter eine derart hohe Bedrohung zu stellen, dass die USA sich aus der Region zurückziehen. ${ }^{69}$

Die A2/AD-Bedrohung wird durch verschiedene Waffensysteme konstituiert. Dazu gehören sogenannte Aufklärungs-Streik-Komplexe, die es erlauben, feste US-Einrichtungen und auch Kriegsschiffe in der Region zu zerstören. Zu diesem Zweck hat China massive Investitionen im Bereich Flugzeugbewaffnung, Aufklärungsverbünde, Satelliten und Anti-Satellitentechnologie sowie in der U-Boot-Technologie vorgenommen. China kann mittlerweile US-amerikanische Einrichtungen und Schiffe in einem Umkreis von etwa $2400 \mathrm{~km}$ bedrohen. ${ }^{70}$ China legt in diesem Zusammenhang auch besonders hohen Wert auf Cyber-Kriegsführung und die Nutzung künstlicher Intelligenz. ${ }^{71}$

Die Frage ist, ob daraus eine erhöhte Kriegsgefahr resultiert und über welche Mechanismen ein Krieg zwischen den USA und China ausbrechen könnte. Derzeit gehen viele Beobachter nicht davon aus, dass es zu einem Krieg zwischen den USA und China kommen wird, nicht zuletzt, weil beide Länder wirtschaftlich eng miteinander verflochten sind. ${ }^{72}$ Aber das kann sich ändern und die politische Rhetorik ist in den vergangenen Jahren deutlich feindseliger geworden. Auch die gegenseitige wirtschaftliche Verflechtung nimmt als Folge der Trumpschen „Handelskriege“ ab, bzw. es wird von beiden Seiten versucht, diese zu reduzieren. Manche befürchten, dass, je mehr militärische Optionen China erwirbt, die Neigung der chinesischen Führung umso größer sein könnte, diese im Fall einer Krise auch einzusetzen. Einige Beobachter gehen davon aus, dass binnen weniger Jahre China in der Lage sein wird, im Rahmen eines koordinierten Angriffs einen strategisch signifikanten Schaden an allen bekannten US-Einrichtungen in der Region anzurichten, eine

67 Friedberg 2011, 157.

68 Friedberg 2014, 25; Montgomery 2014, 129-139.

69 Vgl. Krepinevich/Watts/Work 2003, 15.

70 Le Mière 2014, 141.

71 Cliff/Burles/Chase/Eaton/Pollpeter 2007, Shambough 2002.

72 Fingar/Jishe 2013, Montgomery 2014, 131; anders argumentieren jedoch Dupont/Baker 2014. ansehnliche Zahl amerikanischer Kriegsschiffe zu versenken und wesentliche Quellen der nachrichtendienstlichen Aufklärung der USA auszuschalten. ${ }^{73}$ Manche Analysten sprechen schon von einer zweiten Pearl-Harbor-Operation, die drohen könnte. ${ }^{74}$

Wir realistisch das alles ist, ist schwer zu bestimmen. Es hängt davon $a b$, in welcher Situation die chinesische Führung sich sieht und ob sie glaubt, mittels bestimmter technologischer Faktoren ein Übergewicht erzielen zu können - und sei es auch nur innerhalb eines bestimmten Zeitraums. Im Bereich des Cyber War, des Information War und der künstlichen Intelligenz ist es durchaus vorstellbar, dass manche Akteure glauben, einmal erzielte Vorteile rasch anwenden zu müssen, weil ansonsten der Vorsprung schnell wieder von anderen wettgemacht werden könne. ${ }^{75}$ Die chinesische Doktrin des ASCEL legt zudem Wert darauf, zuerst zuzuschlagen und den Gegner hart und in der Tiefe zu treffen. ${ }^{76}$ Nun ist eine Doktrin nicht gleichzusetzen mit einer Strategie für einen bestimmten Kriegsschauplatz, aber sie hat Auswirkungen darauf, wie unter bestimmten Bedingungen eine Militärstrategie entwickelt und der politischen Führung als Option vermittelt wird.

Für die USA bedeutet diese Entwicklung, dass sie sich entscheiden muss, ob sie der chinesischen Herausforderung entgegentreten will oder ob es Alternativen gibt. ${ }^{77}$ Eine entsprechende Debatte wird in amerikanischen Thinktanks und Zeitschriften seit über zwei Jahrzehnten in kontroverser Weise geführt. Hier gibt es zum einen diejenigen, die davon ausgehen, dass es auf die Dauer für die USA keinen Sinn ergebe, mit starken militärischen Kräften in der Region zu verbleiben, weil diese unausweichlich dazu führten, dass China diese Kräfte als Bedrohung ansähe und sie zu neutralisieren versuche. ${ }^{78}$ Die USA würden nicht anders reagieren, sollte China mit Nachbarstaaten Bündnisse schließen und dort Truppen stationieren. Von daher sollten die USA zu einer Strategie des Offshore-Balancing übergehen, d.h. ihre Stützpunkte, Flugzeuge, Kriegsschiffe und Truppen abziehen und alliierte Staaten in der Region erst dann unterstützen, wenn diese wirklich in Not seien. ${ }^{79}$ Andere argumentieren, dass ein Rückzug der USA zum Kollaps der Bündnisse und zur Abwendung

73 Friedberg 2014, 82. White 2012, 74

74 Van Tol/Gunzinger/Krepinevich/Thomas 2010, 20-21. 75 Gompert/Libicki 2014, 7-21.

76 Friedberg 2014, 25.

77 Montgomery 2014, 139.

78 Tellis 2013.

79 Posen 2013, Walt 2011, Layne 2002, Mearsheimer 2010, Kaplan 2010. 
der Staaten Asiens von den USA führen würden. ${ }^{80}$ Sie gehen davon aus, dass eine militärische Neutralisierung der chinesischen ACEL-Strategie möglich sei und derartige Überlegungen auch schon entwickelt und umgesetzt worden seien. Sie verweisen auf das 2012 verabschiedete Joint Operational Access Concept, welches im Mai 2013 durch das Air-Sea-Battle Konzept ergänzt wurde. Beide Papiere zielen darauf ab, bestehende Verwundbarkeiten $\mathrm{zu}$ reduzieren und auch offensiv auf die neuen Herausforderungen einzugehen. ${ }^{81}$ Andere hingegen sehen die Zeit gekommen für einen strategischen Dialog zwischen Washington und Beijing, bei dem es darauf ankomme, sowohl die Bündnisverpflichtungen Washingtons als auch die Sorgen Chinas über die militärische Präsenz der USA in der Region gegeneinander abzuwägen. ${ }^{82}$

Derartige Debatten werden in Deutschland nur in einer engeren Experten-Community verfolgt. Ihre strategische Bedeutung ist jedoch nicht $\mathrm{zu}$ unterschätzen, denn es kann sein, dass von amerikanischer Seite der Fortbestand des Atlantischen Bündnisses davon abhängig gemacht wird, ob die europäischen Alliierten bereit sind, den USA und anderen westlichen Demokratien in Ostasien beizustehen. ${ }^{83}$ Aber noch eine Verbindung zur europäischen Sicherheit und zur Wahrscheinlichkeit von Kriegen existiert: Es mehren sich die Zeichen, dass Russland und China nicht nur militärisch kooperieren, sondern dass sie auch ein Bündnis bilden oder eine bündnisartige Beziehung haben. Viele argumentieren, dass ein derartiges Bündnis bestenfalls einzelne Bereiche umfassen werde, aber wegen der Asymmetrien zwischen beiden Ländern keine Zukunft habe. Dem steht die Ansicht gegenüber, dass Russland und China regionale Kriege an ihrer Peripherie als wahrscheinlich ansehen und die Initiative ergreifen würden und die USA jedes Mal der Alliierte derjenigen Länder wäre, die im Aufmerksamkeitsbereich dieser regionalen Kriege stünden (baltische Staaten und Polen in Europa, Taiwan, unter Umständen auch Südkorea, Japan in Ostasien). Wenn das Bündnis oder die Quasi-Allianz zwischen Moskau und Beijing darauf hinauslaufen würde, dass man sich verabredete, diese regionalen Kriege zum gleichen Zeitpunkt beginnen zu lassen, hätte dies eine ähnlich erschütternde Wirkung wie seinerzeit der MolotovRippentrop-Pakt vom August 1939. Die USA wären damit

80 Montgomery 2014, 148.

81 Cliff/Burles/Chase/Eaton/Pollpeter 2007, 95-103, sowie Ratner 2013 und Tellis 2013.

82 Helene Cooper and Jane Perlez: U.S. Sway in Asia is Imperiled as China Challenges Alliances, New York Times, 31.5.2014, s. a. Manicom 2014; Patalano/Manicom 2014, 343.

83 Vgl. Kamp 2019. überfordert, in zwei Kriegsschauplätze auf einmal einzugreifen. Die Welt wäre danach eine andere. ${ }^{84}$

\subsection{Kriegsgefahr auf der koreanischen Halbinsel}

Die koreanische Halbinsel ist heute diejenige Region, in der weltweit die größte Konzentration von Truppen zu finden ist. Im Norden steht eine Streitmacht von knapp 1,3 Millionen Soldaten unter Waffen (zumeist Landstreitkräfte, die allerdings schlecht ausgerüstet sind). Die Streitkräfte Südkoreas sind mit etwa 600.000 Soldaten deutlich kleiner, gelten als besser ausgerüstet und werden von etwa 30.000 amerikanischen Soldaten unterstützt, die sich dauerhaft im Land befinden. ${ }^{85}$ Die aggressive und unberechenbare Politik der nordkoreanischen Führung und deren Erfolge beim Bau oder Erwerb von Kernwaffen und Raketen geben dem ganzen Konflikt eine Gefährlichkeit, wie man sie selten in der Welt findet.

Das, was den Konflikt seit den 50er-Jahren antreibt, ist der politisch-revolutionäre Machtanspruch der kommunistischen Partei Nordkoreas, der sich nicht nur auf Nordkorea bezieht, sondern auch Südkorea umfasst. Lange Zeit wurde dieser Machtanspruch durch eine Invasionsfähigkeit untermauert, die dazu führte, dass die USA mit einer deutlichen Truppenpräsenz in Südkorea blieben und gleichzeitig halfen, die südkoreanischen Streitkräfte zur Verteidigung gegen einen Angriff aus dem Norden auszustatten. Heute ist die Lage insofern anders, als die Streitkräfte Nordkoreas zwar weiterhin extrem groß sind, aber aufgrund der veralteten Ausrüstung und der ausgezeichneten südkoreanischen Verteidigungsfähigkeiten eine gewaltsame Wiedervereinigung nicht werden erreichen können. Gleichzeitig hat sich Südkorea zu einem dynamischen Industriestaat entwickelt und ist eine funktionierende Demokratie westlichen Zuschnitts geworden ist. Der Norden hingegen ist bezüglich Wirtschaftskraft, Industrialisierung und Lebensqualität weit abgefallen. Die Wirtschaftskraft Südkoreas mit 51 Millionen Einwohnern dürfte etwa 40-mal so groß sein wie diejenige Nordkoreas

$84 \mathrm{Zu}$ diesem Thema haben das ISPK und die Konrad-Adenauer-Stiftung im Januar 2020 ein internationales Symposium zu der Möglichkeit einer russisch-chinesischen Allianz veranstaltet. Am Ende waren sich nahezu alle Teilnehmer einig, dass die Parallelität der Interessen beider Seiten an der Führung von regionalen Kriegen ein zentrales Motiv für ein wie immer geartetes Bündnis sein dürfte. 85 Angaben laut IISS 2020, 284-290. 
(mit seinen 24 Millionen Einwohnern). ${ }^{86}$ Die Revolutionen von 1989 sind an Nordkorea vorbeigegangen, weil die dortige Partei (noch unter Kim Il-Sung) es verstanden hatte, mit äußerst brutalen Mitteln ihre Macht zu wahren.

In den 90er-Jahren gingen die meisten Beobachter davon aus, dass der Weg, den Nordkorea eingeschlagen hatte, nicht dauerhaft durchführbar sei. Entweder drohe die Implosion des Landes oder dieses würde den drohenden Kollaps durch eine Invasion des Südens abzuwenden versuchen. Dem Land bliebe nur die Reform. ${ }^{87}$ Tatsächlich ist keine dieser Optionen eingetreten, wenngleich es begrenzte Reformen in den vergangenen zehn Jahren gegeben hat. Diese blieben aber so weit limitiert, dass aus ihnen keine Infragestellung der repressiven Machtstrukturen erfolgen konnte. Das politische Regime hat sich zu einer quasi-feudalen (sultanistischen) Machtstruktur entwickelt, in der sich Funktionseliten aus Partei und Sicherheitsapparat unter Anwendung extremer Gewalt, vielfältiger Unterdrückungsmaßnahmen und einer totalitären Kontrolle der Information und des Erziehungswesen an der Macht halten konnten. ${ }^{88}$ Die Partei hat sich zu einer Machtvertikale entwickelt, die Politik, Wirtschaft und Militär fest unter Kontrolle hat, und ein Alleinherrscher bestimmt darüber, wer in dieser Machtvertikale welche benefits erhält und er ist auch in der Lage, diese wieder fortzunehmen. ${ }^{89}$ Darin ähnelt das Land durchaus Russland, aber da Nordkorea über keine Reichtümer verfügt und zudem immer noch an einer Ideologie festgehalten wird, die eine koreanische Variante des Kommunismus darstellt, haben wir es in Nordkorea mit einem totalitären System zu tun, dessen herrschende Klasse sich mittels einer Ausbeutung der Arbeit der normalen Menschen bereichert.

Diese Politik Pjöngjangs war und ist nur möglich, weil China seine Hand über das Regime hält. Zwar ist die Wertschätzung in Beijing für die politische Klasse Nordkoreas gering, aber die Beibehaltung und damit auch die Stützung des Regimes ist ein wichtiger Pfeiler der Asienpolitik Chinas. Ziel ist es, die Wiedervereinigung Koreas nach deutschem Vorbild zu vermeiden, weil das bedeuten könnte, dass ein mit den USA verbündeter Staat direkt an China angrenzen würde - möglicherweise noch mit amerikanischen Truppen im Land. Für China ist Nordkorea

86 Das Bruttosozialprodukt Nordkoreas ist nicht bekannt, es wurde vom CIA für 2015 auf etwa 40 Mrd. US Dollar geschätzt, das Bruttosozialprodukt Südkoreas lag in den vergangenen Jahren zwischen 1,6 und 1,8 Billionen US Dollar

87 Green 1997, 7.

88 Vgl. Byman/Lind 2010.

89 Isozaki 2017, $37 \mathrm{ff}$. daher ein Pufferstaat, den man nicht steuern, aber den man nutzen kann, um den Einfluss der USA zurückzudrängen. ${ }^{90}$

Die Führung in Nordkorea hat diese Lage genutzt, um einen politischen Korridor entstehen zu lassen, innerhalb dessen es Kernwaffen entwickeln, herstellen und testen konnte. Diese dienen primär der Abschreckung gegen eine befürchtete Invasion Südkoreas und der USA, aber sie haben den Zweck der innenpolitischen Stabilisierung und verleihen Pjöngjang die Möglichkeit der politischen Erpressung. ${ }^{91}$ Es gibt seit Anfang der 90er-Jahre internationale Bemühungen um eine Verhandlungslösung mit der Führung in Pjöngjang mit dem Ziel, einen Verzicht auf das Nuklearwaffenprogramm im Gegenzug zu Sicherheitszusagen und Hilfeleistung bei einer Wirtschaftsreform zu erreichen. Diese Verhandlungen wurden in unterschiedlichen Formaten (bilateral, Sechsergruppe) durchgeführt und 2019 nahm sich US-Präsident Donald Trump der Angelegenheit selber an. Entweder blieben sie erfolglos oder sie führten zu Vereinbarungen, die zumeist von Nordkorea in Frage gestellt, gebrochen oder umgangen wurden oder auch daran scheiterten, dass die USA Zusagen für Hilfeleistungen nicht einhalten konnten oder nicht konsequent in ihrer Politik waren..$^{92}$ Der Sicherheitsrat hat seit 2006 mehrere Sanktionen gegen Nordkorea verhängt, ebenso die USA und andere Staaten. Die Sanktionen werden regelmäßig durch China umgangen, welches verhindern will, dass das Regime kollabiert. ${ }^{93}$

Das Kernwaffenprogramm - ähnlich wie das dazugehörige Raketenprogramm - geht auf die Zusammenarbeit Nordkoreas mit der Sowjetunion in den 70er- und 80er-Jahren zurück. Nordkorea hatte aus der Sowjetunion einen Forschungsreaktor erhalten, der die Basis für das Plutoniumprogramm bildete. Zudem konnte es Scud-Raketen aus vorgefertigten Teilen nachbauen bzw. modifizieren. Nach der Auflösung der Sowjetunion hat das Land offenbar auch sowjetische Kernwaffenexperten und Raketenexperten abwerben können, die die Programme vorangetrieben haben. Auf dem Gebiet der ehemaligen Sowjetunion gab es zudem Möglichkeiten, Material für den Bau von Kernwaffen und Raketen abzuzweigen. Das Uran-Anreicherungsprogramm, welches Anfang des neuen Jahrtausends bekannt wurde, ist offenbar mit Technologie betrieben worden, die aus Pakistan (A. Q. Khan)

90 Isozaki 2017, 48, zu den komplexen Beziehungen zwischen China und Nordkorea vgl. Nanto/Manyin 2011.

91 Vgl. Bracken 1993, siehe auch Habib 2011.

$92 \mathrm{Zu}$ den Verhandlungen vgl. Pritchard 2007, Pollack 2017, Niksch 2010

93 Noland 2009. 


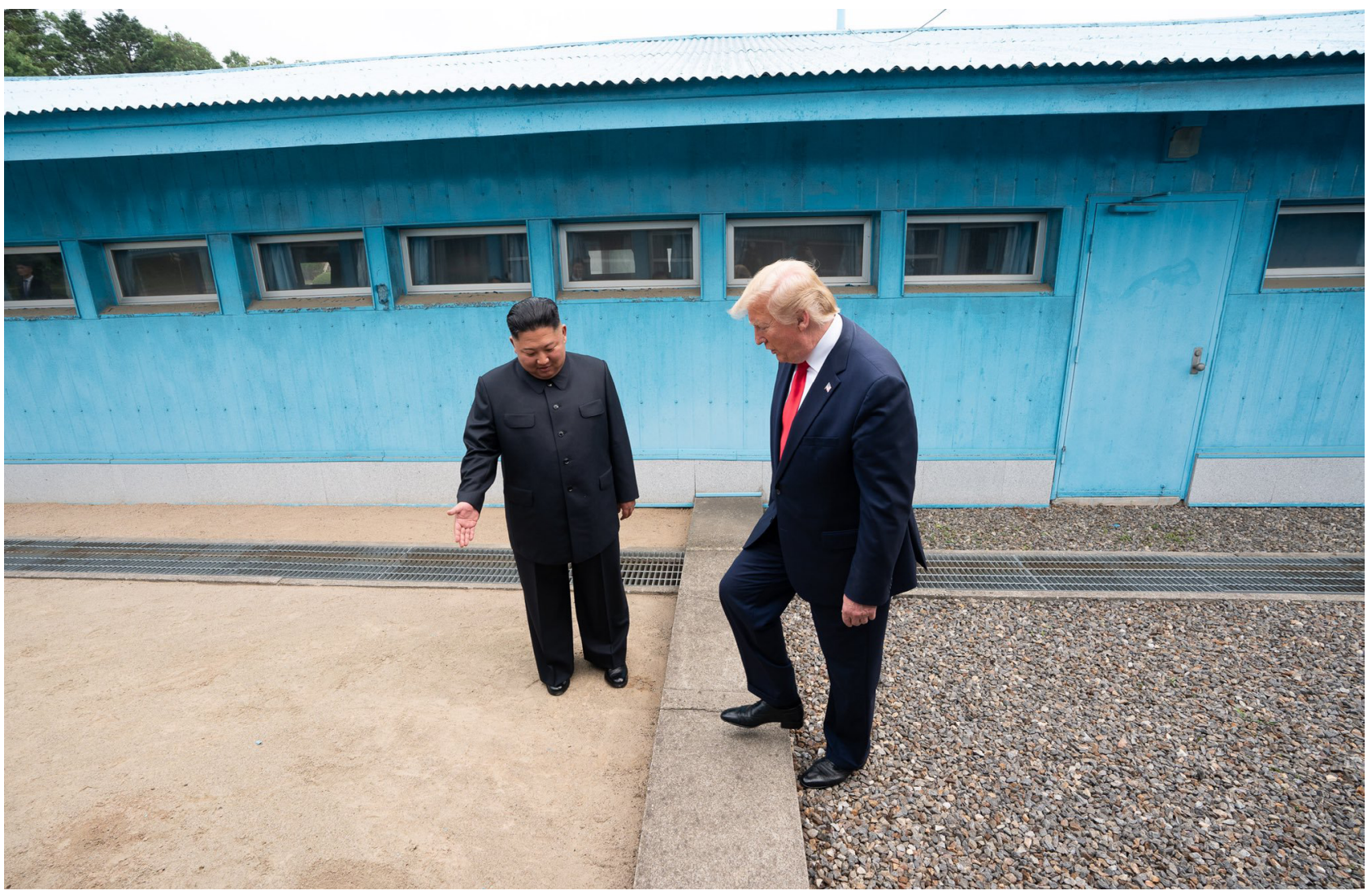

Präsident Trump und Kim Jung-un treffen sich in Panmunion

kam. In der Literatur finden sich auch viele Hinweise auf technische Hilfe Chinas beim Raketenbauprogramm. ${ }^{94}$ Es sind allerdings auch Zweifel darüber aufgekommen, ob Nordkorea mit der beschränkten industriellen und technologischen Basis in der Lage ist, ein Raketenprogramm technisch durchzuführen, welches über eine ganze Reihe unterschiedlicher Raketen (mit verschiedenen Entwicklungslinien) und interkontinentalen Reichweiten verfügt. ${ }^{95}$ Diese Frage ist berechtigt. Ein Land mit dem Bruttosozialprodukt von 40 oder vielleicht $50 \mathrm{Mrd}$. US Dollar, welches keine nennenswerte industrielle Basis hat und nicht in der Lage ist, einfache Fahrzeuge oder Flugzeuge herzustellen, stellt plötzlich Raketen großer Reichweite her, die von hochmodernen, selbstfahrenden Startlafetten mit 8 bis 9 Achsen abgefeuert werden. Von daher ist die Frage schon berechtigt, inwieweit China und auch Russland hier nachgeholfen haben. Beiden ist zwar das Nuklearwaffenprogramm Nordkoreas auch nicht recht, aber

94 Die Informationen zu der Entwicklung des Nuklearwaffenprogramms und des Raketenprogramms sind zusammengefasst bei Niksch 2010, 17-21.

95 Schmucker/Schiller 2017. wenn dieses dazu beitragen kann, dass die Beziehungen Seouls zu Washington belastet werden, kann das politisch allemal sinnvoll sein. ${ }^{96}$

Was folgt aus diesen Überlegungen für die Kriegsgefahr? Im Prinzip ist die Kriegsgefahr gering, denn das Land, von dem ein Krieg seinen Ausgang nehmen könnte Nordkorea -, hat keine realistischen Offensivoptionen und befindet sich in der Defensive. Die Verfügung über Kernwaffen bietet Pjöngjang ausreichende Aussicht darauf, dass diese Abwehrstrategie (oder Abschreckungsstrategie) auch tatsächlich funktioniert. Allerdings gibt es Entwicklungen und Dynamiken, die Zweifel daran aufkommen lassen, ob dieser Zustand lange anhalten wird. Zum einen kann nicht ausgeschlossen werden, dass die politisch isolierte, sektiererische Führung Nordkoreas Kernwaffen in einer Situation einsetzt, wo sie irrtümlich glaubt, dass ein Angriff der USA und Südkoreas gegen sie vorliegt. Nordkorea hat kein funktionierendes Frühwarnsystem, seine Aufklärung dürfte auch im Hinblick auf militärische Aktivitäten der USA in Ostasien begrenzt

96 Siehe Fels 2017, sowie Kim/Warden 2020, Narang/Panda 2020, und Campbell/Dodge 2020. 
und in hohem Maße abhängig von dem sein, was Beijing an Informationen zur Verfügung stellt. Es ist zudem verwundbar für Angriffe und könnte auf Fehlmeldungen über eine konventionelle Invasion Südkoreas und der USA mit einer übereilten nuklearen Reaktion antworten. ${ }^{97}$ Zum anderen muss davon ausgegangen werden, dass die VR China weiterhin das Nuklearprogramm Pjöngjangs dazu nutzt, um einen Keil zwischen die USA und Südkorea zu treiben. Dazu dienen vor allem die vielen Raketentests, die offensichtlich primär keinen technischen Hintergrund haben, sondern dazu dienen, Entschlossenheit und das vermeintliche Überspringen technologischer Hürden zu demonstrieren..$^{98}$ Es ist in diesem Zusammenhang auch durchaus vorstellbar, dass Südkorea, welches heute über moderne Streitkräfte verfügt, eines Tages selbst die Initiative ergreift, um diese extrem angespannte Situation mit einem Befreiungsschlag zu beenden. Aber dagegen spricht die Gefahr einer nuklearen Reaktion Nordkoreas.

\subsection{Indien und Pakistan}

Ein weiterer Hotspot, an dem es Kriegsgefahr zu vermuten gilt, ist Südasien, genauer gesagt, die Konfrontation zwischen Indien und Pakistan. In dieser Konfrontation findet sich alles wieder, was laut Clausewitz auf Kriegsgefahr hinausläuft: tief sitzender gegenseitiger Hass und darauf aufbauend der immer wieder aufflammende Wille zur Lösung des Streites durch Kampf sowie das hohe Rüstungsniveau schon in Friedenszeiten. Indien unterhält Streitkräfte in der Größenordnung von 1,5 Millionen Soldaten, Pakistan von $654.000 .{ }^{99}$ Beide Länder verfügen zudem über Kernwaffen, erst Indien, später Pakistan, wodurch die militärische Asymmetrie zwischen beiden partiell wettgemacht wird. ${ }^{100}$ Beide Länder haben Kernwaffenarsenale in der Größenordnung von über 100 Sprengköpfen, die zu einem Großteil durch ballistische Raketen oder Flugzeuge ausgebracht werden können. Während in Indien das Militär unter starker ziviler Kontrolle steht, verfügt in Pakistan das Militär ziemlich souverän über die Kernwaffen. ${ }^{101}$ Ein Wettrüsten bei Kernwaffen vergleichbar dem zwischen den USA und der Sowjetunion wird offensichtlich von beiden Seiten wegen der damit verbundenen wirtschaftlichen

97 Miller 2020, 26.

98 Schmucker/Schiller 2017, 38.

99 IISS 2020.

100 Zur Entwicklung der Kernwaffenprogramme vgl. Abraham 1998, Salek 2009, Khan 2012.

101 Krepon 2013.
Belastungen nicht verfolgt. ${ }^{102}$ Hinzukommt die Verwicklung Chinas, welches Indien als regionalen Rivalen und Gegner betrachtet und daher Pakistan militärisch unterstützt, was dazu führt, dass Indien sich eingekreist fühlt (ob zu Recht, sei dahingestellt) und entsprechend nervös ist. Die Nervosität wird noch dadurch gesteigert, dass das pakistanische Militär keine Hemmungen hat, auch terroristische Aktionen in Indien durchführen zu lassen.

Seit absehbar ist, dass beide Staaten über operativ einsetzbare Kernwaffen verfügen, lassen sich zwei gegenläufige Trends verfolgen. Zum einen gab es immer wieder (meist von Pakistan) initiierte Krisen, die das Potenzial zu einem großen Krieg unter Einsatz von Kernwaffen hatten. ${ }^{103}$ In keinem dieser Fälle kam es aber zu einer wirklich dramatischen Eskalation. Das dürfte an den Risiken liegen, die beide Seiten sehen, sollte es zum Einsatz nuklearer Waffen kommen. Von daher hat der Besitz über Kernwaffen durchaus einen beruhigenden Effekt auf beide Seiten. Andererseits wird zu Recht darauf verwiesen, dass die Stabilität der nuklearen Konkurrenzlage nicht eingeschätzt werden könne (anders als im amerikanisch-russischen Verhältnis). Angesichts der geografischen Nähe beider Länder und der damit verbundenen kurzen Vorwarnzeiten, so die Annahme, stoße das nukleare Krisenmanagement sehr schnell an seine Grenzen. ${ }^{104}$ Von daher kann es nicht ausgeschlossen werden, dass die nächste oder übernächste Krise über Kaschmir oder einen Terroranschlag in eine größere militärische Konfrontation übergeht, bei der eine Seite (vermutlich eher Pakistan als Indien) glaubt, Kernwaffen einsetzen zu müssen, um eine drohende Niederlage abzuwenden.

\subsection{Naher Osten}

Von Kriegsrisiken im Nahen Osten zu sprechen, ist insofern etwas irreführend, als es dort schon mehrere Kriege gibt:

- Das ist zum einen der „Bürgerkrieg“ in Syrien, der sich inzwischen zu einem internationalen Konflikt entwickelt hat, bei dem es dem Regime Assads gelungen ist, militärische Unterstützung durch Russland und den Iran zu bekommen. Der Aufstand gegen das Assad-Regime ist weitgehend von islamistischen Milizen dominiert worden, die teilweise - aber auch nur hinhaltend - Unterstützung aus der Türkei und

102 Salek 2009, 232. 103 Siehe die Diskussion bei Gagney 2004, Chari 2004, Narang 2009. 104 Miller 2020, $24 \mathrm{f}$. 
einzelnen Kräften aus dem Kreis der Golfstaaten erhalten. Die Brutalität der Kriegsführung (vor allem von Seiten des Assad-Regimes und seiner russischen und iranischen Helfer) ist in der jüngeren Geschichte ohne Parallele und das damit verbundene humanitäre Desaster eines der größten seit dem Ende des Zweiten Weltkrieges (500.000 Todesopfer, 5 Millionen Auslandsflüchtlinge, 6 Millionen Inlandsflüchtlinge). Der Krieg dürfte absehbar mit einem Sieg der Regierung Assad gegen dessen innenpolitische Gegner enden, damit dürfte die Gewalt im Lande jedoch nicht aufhören. Schon jetzt ist ein Programm zur Umsiedlung der Bevölkerung abzusehen, bei dem mehrheitlich schiitisch und alawitisch bevölkerte Zonen einen Korridor $\mathrm{zu}$ den schiitisch bewohnten Gebieten Iraks bilden sollen - unterstützt und beschützt durch schiitische Milizen, die ihre Anordnungen aus Teheran beziehen. Der Staat Syrien wird auch nach einem militärischen Sieg der Regierung Assad und dessen Hilfstruppen schwach und zerstört bleiben, es sei denn, es gäbe ein großes Aufbauprogramm von außerhalb. ${ }^{105}$

- Zweitens gibt es im Jemen seit 2014 mehrere Kriege im Inneren des Landes, die ausländische Mächte (Iran, Saudi-Arabien, Vereinigte Arabische Emirate) dazu veranlasst haben, auf unterschiedliche Weise zu intervenieren. In erster Linie ist hier der Konflikt zwischen der international anerkannten Regierung von Abed Rabbo Mansur Hadi und den vom Iran unterstützten Huthi-Milizen zu nennen, aber auch der Versuch des Südens, sich vom Norden abzutrennen. Hinzukommt, dass Al-Qaida und der Islamische Staat im Jemen ihre eigenen Kriege gegen die anderen Kriegsparteien führen. Am meisten Aufmerksamkeit zieht der Konflikt zwischen Huthis und der Regierung Hadi auf sich, der sich $\mathrm{zu}$ einem erbitterten Krieg entwickelt hat, unter dem die Bevölkerung massiv leiden muss. Das Ausmaß der humanitären Katastrophe dürfte ein ähnliches Niveau haben wie in Syrien.

- Drittens gibt es mehrere eingefrorene Konflikte in der Region, dazu gehört der Konflikt zwischen der Hisbollah (im Süden Libanons) und Israel, nachdem es $2006 \mathrm{zu}$ einem offenen Krieg gekommen war. Aber auch der Konflikt zwischen der Hamas (im Gaza-Streifen) und Israel gehört dazu. Ein weiterer schwelender Konflikt ist der zwischen der schiitischen Hisbollah im Libanon und den sunnitischen und christlichen Parteien und Milizen im Libanon.
- Des Weiteren gibt es den Konflikt zwischen der Türkei und Kurden, vor allem, nachdem diese im Nordirak und im Nordosten Syriens eigene Formen von Staatlichkeit erringen konnten.

- Nicht zuletzt sind die vielen kleinen bewaffneten Konflikte zu erwähnen, die infolge des Auftretens des Islamischen Staates oder anderer extrem islamistischer Milizen im ganzen Nahen Osten zu verzeichnen sind. Das betrifft die Reste des Islamischen Staates in Syrien und im Irak, den Kampf Ägyptens gegen islamistische Extremisten auf dem Sinai sowie die Beteiligung des Islamischen Staates und Al-Qaeda am Jemen-Krieg oder auch in Nordafrika.

Das, was in der deutschen Diskussion am meisten Sorge $\mathrm{zu}$ bereiten scheint, ist, dass der Konflikt zwischen dem Iran auf der einen Seite und den USA und den mit ihnen verbündeten Staaten des Golf-Kooperationsrates auf der anderen Seite zu einem großen Krieg eskalieren könnte. Tatsächlich sind die Militärpotenziale auf beiden Seiten groß. Der Iran verfügt über Streitkräfte in der Größenordnung von 610.000 Soldaten, die Staaten des Golf-Kooperationsrates haben weniger große Streitkräfte (375.000), sind dafür aber besser ausgerüstet und haben vor allem Unterstützung durch die USA, die mehrere Stützpunkte in der Region unterhalten. ${ }^{106}$ Der revolutionäre Impuls der Politik Teherans bleibt ungebrochen, der Hass in der sunnitisch-arabischen Welt auf den Iran bleibt groß, und die USA verfolgen eine Politik der Isolierung und Konfrontation des Irans. Dennoch sind die Aussichten darauf, dass daraus ein großer Krieg resultieren könnte, noch relativ gering. Dafür sprechen folgende Gründe:

- Keine der beteiligten Parteien verfügt über Streitkräfte, die in der Lage wären, die jeweils andere Seite $\mathrm{zu}$ Lande anzugreifen und dauerhaft $\mathrm{zu}$ besetzen. ${ }^{107}$ Die USA wären theoretisch dazu imstande, aber erst nach einer mehrmonatigen Vorbereitungszeit (wie Ende 2002 gegen den Irak). Angesichts der Erfahrungen mit der Besetzung des Iraks und den enormen Kosten des Wiederaufbaus (und den mageren Resultaten) wird es in absehbarer Zeit keinen amerikanischen Präsidenten geben, der eine solche Invasion gegen den Iran anordnen wird (abgesehen vom Widerstand im Kongress).

- Während die USA und die Staaten des Golf-Kooperationsrates eine eindeutige Überlegenheit bei Kampfflugzeugen und bei größeren Marineeinheiten haben und 
somit in der Lage sind, wertvolle Ziele im Iran anzugreifen, hat sich der Iran darauf konzentriert, verschiedene Formen asymmetrischer Angriffsmöglichkeiten zu entwickeln. Dazu zählen Angriffe auf militärische oder zivile Einrichtungen durch schiitische Milizen oder andere Proxies, aber auch mittlerweile sehr zielgenaue (anonyme) Angriffe mit Drohnen und Raketen gegen hochwertige zivile Ziele (wie Erdölförderanlagen, Entsalzungsanlagen, kommerzielle Schiffe etc.). Eine Eskalation in diesem Bereich ist denkbar, sie wird aber kaum über Tit-for-tat-Angriffe hinausgehen. ${ }^{108}$ Das bedeutet, es wird keine Seite einen militärischen Erfolg im Sinne der Zerstörung der Kampfkraft der anderen Seite erreichen können. Eher stellt sich eine Symmetrie der Optionen dar, die zu einem Gleichgewicht der gegenseitigen Abschreckung führt. ${ }^{109}$

Diese Konstellation kann sich ändern, entweder in die eine oder die andere Richtung. Die derzeitige US-Administration hat offenkundig keine klaren Vorstellungen davon, was sie in der Region erreichen und bewirken will. Äußerungen von Präsident Trump lassen den Schluss zu, dass dieser sich ganz aus der Region zurückziehen will, sein Militär hält das für einen schweren Fehler. Sollten sich die USA zurückziehen, würde das Gleichgewicht zugunsten des Irans kippen. Entscheidend sind aber auch noch andere Faktoren: das Maß an Einigkeit und Uneinigkeit unter den Staaten des Golf-Kooperationsrates, insbesondere die Rolle Saudi-Arabiens als Führungsmacht; die innenpolitische Lage im Irak, aber auch die Grenzen der wirtschaftlichen Leistungsfähigkeit des Iran, insbesondere unter dem Einfluss der Corona-Virus-Krise, die den Iran ganz besonders getroffen hat. Sollten sich die Fähigkeiten des Iran angesichts eines imperialen overstretch erschöpfen, könnte das wiederum ganz andere Folgen haben.

Eine weitere Situation der gegenseitigen Abschreckung findet sich derzeit im Konflikt zwischen Israel und der Hisbollah bzw. dem Iran. Die Hisbollah-Miliz hat in den vergangenen Jahren aus dem Iran ein enormes Arsenal an Raketen unterschiedlicher Reichweite und Zielgenauigkeit erhalten (etwa 120.000 Stück), die allesamt auf Israel gerichtet sind und dort trotz einer sehr leistungsfähigen Luftraumabwehr im Ernstfall großen Schaden anrichten würden. ${ }^{110}$ Das ist ein ernstzunehmendes Bedrohungspotenzial, welches nicht den Staat Israel zerstören kann, sondern vermutlich nur verhindern soll, dass Israel Militärschläge gegen iranische Nukleareinrichtungen vornimmt. Was Israel eigentlich hätte beruhigen sollen, war die Tatsache, dass der Iran nach der Verhängung massiver internationaler Sanktionen nach jahrelangen Verhandlungen im Jahr 2015 eingewilligt hat, sein Nuklearprogramm mehr oder weniger weitgehend einzufrieren. Dies geschah im Rahmen des Joint Comprehensive Plan of Action (JCPOA), den eine Gruppe - bestehend aus den fünf ständigen Mitgliedern des Sicherheitsrates und Deutschland - mit der Regierung in Teheran ausgehandelt hatte. Daraus hätte sich ein ungefähres Gleichgewicht der Optionen ergeben können, welches zumindest vorübergehend eine gewisse Stabilität geschaffen hätte. Aber Israel hat dem Abkommen nicht getraut, vor allem, weil es keine Bestimmungen zum Einfrieren des iranischen Raketenrüstungsprogramms vorsieht und weil der Iran seit 2015 auch keine Anstalten machte, von dem erklärten Ziel der Vernichtung Israels abzuweichen. ${ }^{111}$ Mit der Aufkündigung des JCPOA durch Präsident Trump im Mai 2018 hat sich die Frage weitgehend erledigt, wie lange mit dem Abkommen der Gleichgewichtszustand hätte beibehalten werden können. Der Iran hat mittlerweile sein Uran-Anreicherungsprogramm wieder aufgenommen und verkürzt somit die Anlaufzeit bis zum Erreichen der notwendigen Menge für den Bau mindestens einer Bombe kontinuierlich. ${ }^{112}$ Diese dürfte mittlerweile deutlich unter einem Jahr liegen.

Damit rückt die Möglichkeit in große Nähe, dass es zwischen Israel und dem Iran zu einem Krieg kommt, bei dem es Israel um die nachhaltige Zerstörung des iranischen Kernwaffenprogramms geht. Israel wird nicht zögern, dieses Programm zu zerstören, sollte der Iran auch nur in die Nähe der Vervollständigung eines oder mehrerer Kernsprengköpfe gelangen. Die Logik Israels ist nachvollziehbar: Die politische Führung im Iran - gleich ob revolutionäre Eiferer oder Reformer - fordert seit Jahrzehnten die Auslöschung oder Vernichtung Israels. Angesichts der geringen territorialen Ausdehnung Israels (der bewohnbare Teil ist kleiner als Schleswig-Holstein) würden schon ein oder zwei Kernwaffenschläge das Ende Israels bedeuten. Die Mittel zur Zerstörung des Programms besitzt Israel: konventionell und auch atomar. Sollte ein konventioneller Angriff nicht ausreichen, wäre es nicht auszuschließen, dass Israel zuerst Atomwaffen gegen den Iran einsetzt.

111 Rubin 2020

112 Wahdat-Hagh/Krause 2019.
108 IISS Strategic Comment, 17.3.2020: The Soleimany's Killing regional Implications.

109 Cordesman 2020, $217 \mathrm{ff}$.

110 Karmon 2019. 


\subsection{Sonstige Kriegsgefahren}

Diese hier genannten Szenarien betreffen diejenigen Kriegsgefahren, die von großer strategischer Relevanz sind und die in großen und verlustreichen Kriegen enden können - auch solchen, bei denen es zum Einsatz von Kernwaffen kommt. Daneben wird es natürlich auch weitere kleine Kriege von der Art geben, wie wir sie seit Jahrzehnten in Afrika, Asien und Lateinamerika beobachten können. Das sind Sezessionskriege, Kriege um den Einfluss von politischen Parteien oder von tribalen Organisationen innerhalb eines Landes, Kriege, die die Rivalität unterschiedlicher Clans widerspiegeln oder bei denen es darum geht, religiöse Heilsbotschaften zu verbreiten und generell einen Krieg gegen die westliche Zivilisation zu führen. Mehr und mehr finden sich auch Kriege, bei denen Parteien weitgehend davon leben, dass sie Krieg führen, weil der Krieg sie ernährt. Diese Art von Kriegen wird es auch weiterhin geben, sie haben ihren Nährboden in mangelnder Staatlichkeit, aber auch darin, dass das, was funktionierende Staatlichkeit voraussetzt (Kompromissbereitschaft, Denken in gesamtstaatlichen Kategorien, Verständnis politischer Ämter als eine Verpflichtung und nicht als Möglichkeit der Selbstbereicherung), selten vorhanden ist. ${ }^{113}$

Darüber hinaus wird es wohl kaum noch Fälle von Kriegen geben, die von US-geführten Koalitionen unternommen werden, um Ziele im Sinne der Ordnung der kollektiven Sicherheit zu verfolgen (seien es humanitäre Interventionen in einem asymmetrischen Bürgerkrieg, sei es um einen Genozid zu verhindern, einen ständig Kriege beginnenden Diktator zu stürzen oder um die Wiederherstellung von Staatlichkeit in einem zerfallenden Land militärisch zu unterstützen). Der größte dieser Kriege der gewaltsame Regimewandel im Irak 2003 - und dessen Folgen haben ebenso wenig wie der ISAF-Einsatz in Afghanistan oder der MINUSMA-Einsatz in Mali die erwarteten Erfolge gebracht. Erfolgreicher waren die Interventionen auf dem Balkan 1995 und 1999 zur Beendigung einer humanitären Katastrophe, die durch die serbische Kriegsführung verursacht worden war. Aber zu einer Lösung der Probleme haben diese Interventionen nicht beigetragen. Tatsächlich sind die Kosten in die Höhe gestiegen: Der IrakKrieg hat die amerikanischen Steuerzahler mehr als eine Billion US-Dollar gekostet, der Afghanistan-Einsatz nicht viel weniger. ${ }^{114}$ Schon der amerikanische Präsident Barack

113 Chowdhury 2018.

114 Kevin Maurer: Witness to a War, Washington Post Magazine, 9.9.2019.
Obama hatte die amerikanischen Engagements zurückgefahren, Donald Trump ist noch weniger darauf versessen, sein Land in internationalen Interventionen zu verschleißen. Trotz gelegentlicher starker Worte und verstörender Rhetorik ist er ein Präsident, der militärischen Abenteuern und Interventionen grundsätzlich kritisch gegenübersteht. Unter den europäischen Akteuren ist Frankreich das einzige Land, welches in Nordafrika Interventionen unternimmt, die der Stabilisierung und Friedenswahrung dienen sollen. Aber auch dort ist die Frustration über die geringen Erfolgsaussichten ebenfalls gering. Zudem sind die militärischen Fähigkeiten Frankreichs begrenzt. ${ }^{115}$ Als Folge des Ausbleibens von Interventionen demokratischer Staaten, die nicht egoistische Ziele verfolgen, sondern sich den Zielen und Prinzipien kollektiver Sicherheit verpflichtet fühlen, wird es in Bürger- und Sezessionskriegen vermehrt zu Interventionen anderer Mächte kommen, die ihre eigenen machtpolitischen Interessen verfolgen. Die Folgen sieht man schon jetzt in Syrien oder im Jemen: humanitäre Katastrophen, die durch externe Interventionen oder durch lokale Akteure entstehen, gegen die niemand etwas unternimmt, und - als Sekundärfolge - machtpolitische Verschiebungen, die die Basis legen können für künftige größere Kriege.

\section{Resümee}

Fasst man die Ergebnisse zusammen, so ist festzuhalten, dass Aussagen über die Wahrscheinlichkeit von Kriegen im kommenden Jahrzehnt machbar sind, wenngleich diese natürlich mit Vorbehalten und Ungewissheiten einhergehen. Vor Überraschungen ist man nie sicher, aber es lassen sich Trends absehen, wenn man ganz im Sinne von Clausewitz auf das Zusammentreffen von feindseligen Absichten und großen Militärpotenzialen achtet und wenn man gleichzeitig die absehbaren Folgen und Schäden miteinbezieht. Folgt man diesen Methoden, so gelangt man zu Trendaussagen, die wenig mit dem vorherrschenden Narrativ in Politik, Publizistik und Wissenschaft in Deutschland gemein haben, demzufolge Kriege als Bürger- und Sezessionskriege hauptsächlich in unterentwickelten Regionen vorkommen, aufgrund von Missverständnissen und Rüstungswettläufen entstehen oder durch falsch beratene US-amerikanische Präsidenten in Gang kommen. Tatsächlich legen die hier festgestellten Trends nahe, dieses Narrativ nicht nur in Frage zu stellen,

115 Ruth Maclean: Crisis in the Sahel becoming France's War for ever, New York Times, 29.3.2020. 
sondern auch die deutsche Politik auf Situationen vorzubereiten, die nicht oder nur teilweise wahrgenommen werden. Diese Trends, die für das kommende Jahrzehnt ihre Gültigkeit beanspruchen können, sehen wie folgt aus:

- Die größte und nachhaltigste Kriegsgefahr geht in den nächsten zehn Jahren von dem Anspruch der VR China auf eine gewaltsame „Wiedervereinigung“ mit der Republik Taiwan aus. Sollte China seine Drohung wahrmachen, die Insel mit Gewalt zu vereinnahmen, droht angesichts der beiderseitigen hohen Rüstungsanstrengungen nicht nur ein extrem verlustreicher Waffengang, sondern auch eine amerikanisch-chinesische Konfrontation mit Weiterungen, die bis $\mathrm{zu}$ einem Weltkrieg führen können.

- Die zweitgrößte Kriegsgefahr droht im Nahen Osten mit einem direkten Krieg zwischen Israel und dem Iran, wobei, weil es um die Existenz Israels geht, auch der Einsatz von Kernwaffen wahrscheinlich wird.

- Die drittgrößte Kriegsgefahr sind die von Russland ausgehenden regionalen Kriege entweder am Schwarzen Meer (gegen die Ukraine) oder im Ostseeraum gegen die baltischen Staaten. Trotz ihrer regionalen Begrenztheit können derartige Kriege (insbesondere gegen die NATO-Mitglieder Estland, Lettland und Litauen) entweder zu einem großen Krieg zwischen Russland und dem Westen oder aber zum Zerfall des Westens führen, was wiederum Auswirkungen auf den Frieden in Europa hätte.

- Das größte denkbare Unglück in diesem Zusammenhang wäre, wenn sich Russland und China absprächen, die von ihnen vorbereiteten regionalen Kriege (gegen Taiwan bzw. gegen die baltischen Staaten) zum gleichen Zeitpunkt beginnen zu lassen.

- Auch die Lage zwischen Indien und Pakistan bleibt kritisch, der Ausbruch eines größeren Krieges kann in den nächsten zehn Jahren nicht ausgeschlossen werden, auch nicht der Einsatz von Kernwaffen.

- Ansonsten wird es weiterhin Bürgerkriege, Staatenzerfallskriege, Sezessionskriege und Banditenkriege geben. Diese Kriege sind das Resultat nicht vorhandener oder verfallener Staatlichkeit oder - viel häufiger - von Staatlichkeit, die von einzelnen Gruppen oder Clans zur eigenen Bereicherung missbraucht wird. Unterentwicklung als Ursache zu benennen, ist zwar nicht grundlegend falsch, der Begriff bleibt aber weitgehend unspezifisch. Tatsächlich sind es meistens Fehler, die Menschen zu verantworten haben, die diese Unterentwicklung perpetuieren und zu gewaltsamen Formen der Auseinandersetzung führen. Dazu gehören religiöse, ideologische und politische Intoleranz, die Unfähigkeit Kompromisse einzugehen und das Unvermögen, Nationalstaaten ebenso wie internationale Organisationen als Rahmen zu sehen, innerhalb dessen große Probleme angegangen und gelöst werden können.

Für die deutsche Politik bedeutet diese Analyse, dass es größeren Anpassungsbedarf geben muss:

1. Deutsche Politik muss lernen, weniger therapeutisch und wieder stärker strategisch aufgestellt zu sein. Therapeutisch ist eine Politik, die davon ausgeht, dass Kriege aus Missverstehen und Rüstungswettläufen resultieren oder die Folge von Unterentwicklung sind und daher mit Rüstungskontrolle und Entwicklungshilfe verhindert werden können. Eine strategisch orientierte Politik fragt, wo Bedrohungen unserer Sicherheit wirklich herkommen, wo reale (nicht nur abstrakte) Gefahren lauern und was es zu tun gilt, um diesen Gefahren zu begegnen. Derzeit ist deutsche Außen- und Sicherheitspolitik weitgehend therapeutisch aufgestellt, erst seit 2014 beginnt eine vorsichtige Umorientierung auf die Notwendigkeit, die regionale Bedrohung Russlands gegen die Ukraine und NATO-Partner einzusehen, aber von einer wirklich strategischen Diskussion sind wir weit entfernt.

2. Es ist anzuraten die Kriegsgefahren in Ostasien, insbesondere die eines Eroberungskrieges Chinas gegen Taiwan, stärker in den Blick zu nehmen.

3. Es ist dringend notwendig, die Voraussetzungen dafür zu schaffen, dass die Bundeswehr ihre volle Einsatzstärke nicht erst 2030 erreicht, sondern deutlich früher. Ansonsten steigt die Gefahr eines Krieges im Ostseeraum.

4. Es ist notwendig, innerhalb des Westens das Thema Iran wieder auf die Agenda zu nehmen und gemeinsam mit Verbündeten nach Auswegen aus dem derzeitigen Stillstand zu suchen. Sofern der Iran nicht in den kommenden Monaten reumütig nachgibt oder das dortige Regime zerfällt (was sein kann, aber auch nicht sehr wahrscheinlich ist), bedarf es eines Neuansatzes, der einerseits das JCPOA wiederherstellt, andererseits aber auch dessen Defizite aus dem Weg schafft. Dazu bedarf es allerdings einer US-Administration, die führen und zuhören will, was mit der Trump-Administration vermutlich nicht $\mathrm{zu}$ erreichen ist. 


\section{Literatur}

Abraham, Itty (1998): The Making of the Indian Atomic Bomb: Science, Secrecy and the Postcolonial State. Hyderabad: Orient Longman

Acton, James M. (2020): Cyber Warfare \& Inadvertent Escalation, Deadalus, 149 (1), 133-149

Allison, Graham T. (2017): Destined for War: Can America and China Escape Thucydides's Trap? Boston: Houghton Mifflin Harcourt

Bamberger, Leo (2017): Besprechung des Buches „Arms Races in International Politics. From the Nineteenth to the Twenty First Century“, Sirius - Zeitschrift für strategische Analysen, 2 (4), 406-408

Bergeron, James Henry (2018): Die Dynamik der Abschreckung, Sirius - Zeitschrift für strategische Analysen, 2 (1), 21-31

Blair, Bruce G. (1985): Strategic Command and Control: Redefining the Nuclear Threat. Washington, D.C.: The Brookings Institution

Blair, Bruce G. (1987): Alerting in Crisis and Conventional War, in: Carter/Steinbruner/Zraket 1987, 75-120

Blair, Bruce G. (1993): The Logic of Accidental Nuclear War. Washington, D.C.: The Brookings Institution

Bloch, Johann von (1898): Der zukünftige Krieg in seiner technischen, volkswirtschaftlichen und politischen Bedeutung. 6 Bände. Berlin: Puttkammer \& Mühlbrecht

Boulègue, Mathieu (2017): Fünf Anmerkungen zu Zapad 2017, Sirius - Zeitschrift für strategische Analysen, 1 (4), 387-388

Bracken, Paul (1993): Nuclear Weapons and State Survival in North Korea, Survival, 35 (3), 137-153

Bracken, Paul J. (1983): The Command and Control of Nuclear Weapons. New Haven, Ct.: Yale University Press

Brauß, Heinrich/Krause, Joachim (2019): Was will Russland mit den vielen Mittelstreckenwaffen?, Sirius - Zeitschrift für strategische Analysen, 3 (2), 154-166

Buchan, Alastair (1968): Der Krieg in unserer Zeit. München: C. H. Beck

Burchardt, Lothar (1968): Friedenswirtschaft und Kriegsvorsorge. Deutschlands wirtschaftliche Rüstungsbestrebungen vor 1914. Boppard: Verlag Harald Boldt

Burke, Edmund J./Heath, Timothy R./Hornung, Jeffrey W./Ma, Logan/Morris, Lyle J./Chase, Michael S. (2018): China's Military Activities in the East China Sea. Santa Monica, Cal.: RAND Corp.

Byman, Daniel/Lind, Jennifer (2010): Pyongyang's Survival Strategy: Tools of Authoritarian Control in North Korea, International Security, 35 (1), 44-74

Campbell, lan/Dodge, Michael (2020): Deterring North Korea, Survival, 62 (1), 55-59

Carter, Ashton B. (1987a): The command system. Communication technologies and vulnerabilities, in: Carter/Steinbruner/Zraket 1987, 217-281

Carter, Ashton B. (1987b): Sources of error and uncertainty, in: Carter/Steinbruner/Zraket 1987, 611-640

Carter, Ashton B./Steinbruner, John D./Zraket, Charles A., Hrsg. (1987): Managing Nuclear Operations. Washington, D.C.: Brookings

Chari, P. R. (2004): Nuclear Restraint, Risk-Reduction, and the Security-Insecurity Paradox in South Asia, in: Krepon 2004, 19-41

Chowdhury, Arjun (2018): The Myth of International Order. Why Weak States Persist and Alternatives to the State Fade Away. Oxford und New York: Oxford University Press
Churchill, Winston S. (1948): The Second World War. Vol. 1: The Gathering Storm. London, Toronto u. a.: Cassell \& Co

Chyba, Christopher F. (2020): New Technologies \& Strategic Stability, Deadalus, 149 (1), 150-170

Clark, Christopher (2013): Die Schlafwandler. Wie Europa in den Ersten Weltkrieg zog. München: Pantheon Verlag

Clausewitz, Carl von (1867): Vom Kriege. Hinterlassene Werke über Krieg und Kriegführung des Generals Carl von Clausewitz. Band 1, dritte Auflage, Berlin: Dümmler's Verlagsbuchhandlung

Cliff, Roger/Burles, Mark/Chase, Michael S./Eaton, Derek/Pollpeter, Kevin L. (2007): Entering the Dragon's Lair: The Implications of Chinese Antiaccess Strategies. Santa Monica, Cal.: RAND Corp.

Cordesman, Anthony H. (2020): Iran and the Changing Military Balance in the Gulf. Net Assessment Indicators. Washington, D.C.: CSIS.

Daalder, Ivo/Lindsay, James (2018): The Empty Throne: America's Abdication of Global Leadership. New York: Public Affairs

De Wijk, Rob (2018): Die Rolle von Abschreckung im neuen strategischen Umfeld Europas, Sirius - Zeitschrift für strategische Analysen, 2 (1), 3-20

Dibb, Paul (2019): How the geopolitical partnership between China and Russia threatens the West. Canberra: ASPI

Diniz, Eugenio (2016): Armamentos Nucleares: Dissuasão e Guerra Nuclear Acidental, Carta Internacional, 11(1), 9-62

Dorsey, James M. (2019): The Future of the China-Russia Alliance. Ramat Gam, Isr.: BESA Center for Strategic Studies.

Dupont, Alan/Baker, Christopher G. (2014): East Asia's Maritime Disputes - Fishing in Troubled Waters, The Washington Quarterly, 37 (1), 79-98

Dvorkin, Vladimir (2019): Wie lässt sich in einer Zeit der strategischen Konfrontation zwischen den USA und Russland strategische Stabilität bewahren?, Sirius - Zeitschrift für strategische Analysen, 3 (3), 262-269

Ehlert, Hans/Epkenhans, Michael/Groß, Gerhard P., Hrsg. (2006): Der Schlieffenplan. Analysen und Dokumente. Paderborn: Ferdinand Schöningh Verlag

Engels, Friedrich (1962): Einleitung zu Sigismund Borkheims Broschüre „Zur Erinnerung für die deutschen Mordspatrioten 1806-1807“, Marx-Engels Werke, Band 21, hrsg. vom Institut für Marxismus-Leninismus bei ZK der SED, Berlin-Ost: Dietz Verlag, 346-351.

Fels, Enrico (2017): „Gekommen um zu bleiben.“ Optionen für eine Auseinandersetzung mit der neuen Nuklearmacht Nordkorea, Sirius -Zeitschrift für strategische Analysen, 1 (4), 342-352

Ferguson, Niall (2001): Der falsche Krieg. Der Erste Weltkrieg und das 20. Jahrhundert. Frankfurt: DTV

Fingar, Thomas/Jishe, Fan (2013): Ties that Bind - Strategic Stability in the U.S.-China Relationship, The Washington Quarterly, 36 (4), 125-138

Förster, Stig (1987): Facing 'People's War' - Moltke the Elder and Germany's Military Options after 1871, Journal of Strategic Studies, 10 (2), 209-230.

Förster, Stig (1995): Der deutsche Generalstab und die Illusion des kurzen Krieges, 1871-1914, Kritik eines Mythos, Militärgeschichtliche Mitteilungen, 54 (1995), 61-95

Förster, Stig (1999): Dreams and Nightmares: German Military Leadership and the Images of Future Warfare, 1871-1914, in: Manfred F. Boemeke/Roger Chickering/Stig Förster (Hrsg.): Anticipating Total War. The German and American Experiences, 1871-1914. Cambridge: Cambridge University Press, 343-376. 
Freedman, Lawrence (2003): Evolution of Nuclear Strategy, third edition. London: Palgrave Macmillan

Friedberg, Aaron L. (2011): A Contest for Supremacy. China, America, and the Struggle for Mastery in Asia. New York: W.W. Norton

Friedberg, Aaron L. (2014): Beyond Air-Sea Battle. The Debate over US Military Strategy in Asia. Abington: Routledge for IISS

Fuller, J.F.C. (1923): The Reformation of War. London: Hutchinson \& Co

Fuller, J.F.C. (1928): On Future Warfare. London. Sifton, Praed \& Co.

Fuller, J.F.C. (1961): The Conduct of War: 1789-1961. New York: Da Capo Press

Gagney, Chris (2004): Nuclear Risk Reduction in South Asia. Building on Common Ground, in: Krepon 2004, 43-65

Gettleman, Jeffrey (2010): Africa's Forever Wars. Foreign Policy, 11. 2. 2010 https://foreignpolicy.com/2010/02/11/africasforever-wars/

Geyer, Michael (1986): German Strategy in the Age of Machine Warfare, 1914-1945, in: Paret 1986, 527-597

Goldstone, Jack/Bates, Robert/Epstein, David L./Gurr, Ted Robert/ Lustik, Michael B./Marshall, Monty G./Ulfelder, Jay/Woodward, Mark (2010): A Global Model for Forecasting Political Instability, American Journal of Political Science, 54, (1), 190-208

Gompert, David C./Libicki, Martin (2014): Cyber Warfare and Sino-American Instability, Survival, 56 (4), 7-21

Green, Michael (1997): North Korean Regime Crisis: US Perspectives and Responses, Korean Journal of Defense Analysis, 9 (2), 7-25

Grossman, Derek/Beauchamp-Mustafaga, Nathan / Ma, Logan/ Chase, Michael S. (2018): China's Long Range Bomber Flights. Drivers and Implications. Santa Monica, Cal.: RAND Corp. 2018

Habib, Benjamin (2011): North Korea's nuclear weapons programme and the maintenance of the Songun system, The Pacific Review, 24 (1), 43-64

Hahlweg, Werner (1968): Guerilla - Krieg ohne Fronten. Stuttgart: Kohlhammer

Herz, John H. (1950): Idealist Internationalism and the Security Dilemma, World Politics, 2 (2), 171-201

Heydte, Friedrich August Freiherr von der (1972): Der moderne Kleinkrieg. Würzburg: Holzner

Howard, Michael (1986): Men against Fire. The Doctrine of the Offensive in 1914, in: Paret 1986, 510-526

IISS International Institute for Strategic Studies (2019): The Armed Conflict Survey 2019. London: Routledge for the IISS

IISS International Institute for Strategic Studies (2020): The Military Balance 2020. London: Routledge for the IISS

Ikenberry, G. John (2001): After Victory. Institutions, Strategy Restraint, and the Rebuilding of Order after Major Wars. Princeton und Oxford: Princeton University Press

Ikenberry, G. John (2011): Liberal Leviathan. The Origins, Crisis, and Transformation of the American World Order. Princeton und Oxford: Princeton University Press

Iklé, Fred C. (1958): On the Risk of Accidental or Unauthorized Nuclear Detection. Santa Monica, Cal.: Rand Corporation.

Isozaki, Atsuhito (2017): Understanding the North Korean Regime. Washington, D.C.: The Wilson Center

Johnson, Alastair lain (2019): China in a World of Orders: Rethinking Compliance and Challenge in Beijing's International Relations, International Security, 44 (2), 9-60
Kagan, Robert (2018): The Jungle Grows Back: America and Our Imperiled World. New York: Alfred Knopf

Kaldor, Mary (2012): New and Old Wars: Organized Violence in a Global Era. Cambridge: Polity Press

Kamp, Karl-Heinz (2019): Das strategische Langfrist-Problem der NATO, Sirius - Zeitschrift für strategische Analysen, 3 (2), 129-135

Kaplan, Robert D.: (2010): The Geography of Chinese Power: How far can Beijing reach on land and at sea?" Foreign Affairs, 89 (3), 22-41

Karmon, Ely (2019): Bedrohungen Israels an seiner Nordgrenze, Sirius - Zeitschrift für strategische Analysen, 3 (2),178-183

Khan, Feroz Hassan (2012): Eating Grass: The Making of the Pakistani Bomb. Palo Alto, Cal.: Stanford University Press

Kim, Jina/Warden, Jonathan K. (2020): Limiting North Korea's Coercive Nuclear Leverage, Survival, 62 (1), 31-38

Kirchberger, Sarah (2015): Assessing China's Naval Power. Technological Innovation, Economic Constraints, and Strategic Implications. Berlin: Springer

Kirchberger, Sarah/O'Keefe, Patrick (2019): Chinas schleichende Annexion im Südchinesischen Meer - die strategischen Hintergründe, Sirius - Zeitschrift für strategische Analysen, $3(1), 3-20$

Krause, Joachim (2011): Nach Hiroshima. Die Entwicklung der Theorie des Nuklearkriegs, in: Jäger, Thomas/Beckmann, Rasmus (Hrsg.): Handbuch Kriegstheorien. Wiesbaden: VS Verlag, 413-426

Krause, Joachim (2014): Assessing the Danger of War: Parallels and Differences between Europe in 1914 and East Asia in 2014, International Affairs, 90 (6), 1421-1451

Krause, Joachim (2015a): Strategische Außenpolitikberatung in der Demokratie, in: Sommermann, Karl-Peter (Hrsg.): Sachverständige Politikberatung. Funktionsbedingung oder Gefährdung der Demokratie? Baden Baden: Nomos, 75-101

Krause, Joachim (2015b): Threat Scenarios, Risk Assessments, and the Future of Nuclear Deterrent, in: Hlatky, Séfanie von/ Wenger, Andreas (Hrsg.): The Future of Extended Deterrence. The United States, NATO, and Beyond. Washington, D.C.: Georgetown University Press, 19-39

Krause, Joachim (2017): Strategische Studien in den Internationalen Beziehungen, in: Sauer, Frank/Masala, Carlo (Hrsg.): Handbuch Internationale Beziehungen, 2. Auflage. Wiesbaden: Springer VS, 523-549

Krause, Joachim (2018): Deutschlands Rolle im internationalen Handel mit konventionellen Waffen und Rüstungsgütern: Sind wir die „Waffenkammer der Welt"? SIRIUS - Zeitschrift für strategische Analysen, 2 (2), 137-157

Krause, Joachim (2019): How do Wars End? A Strategic Perspective, Journal of Strategic Studies, 42 (7), 920-945

Krepinevich, Andrew/Watts, Barry/Work, Robert (2003): Meeting the Anti-Access and Area-Denial Challenge. Washington, D.C.: Center for Strategic and Budgetary Assessment.

Krepon, Michael (2013): Pakistan's Nuclear Strategy and Deterrence Stability, in: Michael Krepon, Michael/Thompson, Julia, Hrsg.: Deterrence Stability and Escalation Control in South Asia. Washington, D.C.: Stimson Center, 65-92

Krepon, Michael, Hrsg. (2004): Nuclear Risk reduction in South Asia. London: Palgrave Macmillan.

Kristensen, Hans M./Korda, Matt (2019): Chinese nuclear forces, 2019, Bulletin of the Atomic Scientists, 75 (4), 171-178 
Kroenig, Matthew (2018): Russlands Nuklearstrategie gegenüber Europa. Wie organisiert man Abschreckung gegen Deeskalation mit nuklearen Schlägen?, Sirius - Zeitschrift für strategische Analysen, 2 (4), 323-338

Layne, Christopher (2002): Offshore Balancing Revisited, The Washington Quarterly, 25 (2), 233-248

Le Mière, Christian (2014): The Spectre of an Asian Arms Race, Survival, 56 (1), 139-156,

Liddell Hart, Basil H. (1927): The Remaking of Modern Armies. London: J. Murray

Liddell Hart, Basil H. (1937): Europe in Arms. London: Faber \& Faber

Liddell Hart, Basil H. (1967): Strategy. The Indirect Approach. New York, NY.: Meridian Books

Loukianova Fink, Anya/Oliker, Olga (2020): Russia's Nuclear Weapons in a Multipolar World: Guarantors of Sovereignty, Great Power Status \& More, Deadalus, 149 (1), 37-55

Mahncken, Thomas/Maiolo, Joseph/Stevenson, David (2016): Arms Races in International Politics. From the Nineteenth to the Twenty First Century. Oxford: Oxford University Press

Mandelbaum, Michael (2019): The Rise and Fall of Peace on Earth. Oxford und New York: Oxford University Press

Manicom, James (2014): China and American Seapower in East Asia - Is accommodation Possible? The Journal of Strategic Studies, 37 (3), 345-371

Mann, Christopher T./Fischer, Hannah (2019): Recent Trends in Active-Duty Military Deaths. Washington, D.C.: Congressional Research Service, Update May 2019;

Maull, Hanns (2020): Die Internationale Ordnung. Bestandsaufnahme und Ausblick, Sirius - Zeitschrift für strategische Analysen, 4 (1), 3-23

Mearsheimer, John J. (2010): The Gathering Storm: China's Challenge to US Power in Asia, The Chinese Journal of International Politics, 3 (4), 381-396

Mearsheimer, John J. (2019): Bound to Fail. The Rise and Fall of the Liberal International order, International Security, 43 (4), 7-50

Mearsheimer, John J./Walt, Stephen M. (2016): The Case for Offshore Balancing, Foreign Affairs, 95 (4), 70-83

Menzel, Ulrich (2015): Die Ordnung der Welt. Imperium oder Hegemonie in der Hierarchie der Staatenwelt. Berlin: Suhrkamp Verlag

Meyer zum Felde, Rainer (2018): Abschreckung und Dialogbereitschaft. Der Paradigmenwechsel der NATO seit 2014, Sirius - Zeitschrift für strategische Analysen, 2 (2), 101-117

Miller, Steven E. (2020): A Nuclear World Transformed. The Rise of Multilateral Disorder, Deadalus, 149 (1), 17-36

Moltke, Graf Helmuth von, Generalfeldmarschall (1891): Geschichte des deutsch-französischen Kriegs von 1870-1871. Berlin: Siegfried Mittler (Moltke: Gesammelte Schriften, Band 3)

Mombauer, Annika (2014): Die Julikrise. Europas Weg in den Ersten Weltkrieg. München: C. H. beck

Montgomery, Evan Braden (2014): Contested Primacy in the Western Pacific. China's Rise and the Future of U.S. Power Projection, International Security, 38 (4), 115-149

Mousseau, Michael (2019): The End of War. A Robust Marketplace and Liberal Hegemony are leading to Perpetual World Peace, International Security, 44 (1) 160-196

Müller, Christian Th. (2018): Jenseits der Materialschlacht. Der Erste Weltkrieg als Bewegungskrieg. Paderborn: Schöningh

Müller, Rolf-Dieter (2004): Der Zweite Weltkrieg. Klett-Cotta: Stuttgart (Handbuch der deutschen Geschichte; Band 21)
Münkler, Herfried (2002): Die neuen Kriege. Reinbek: Rowohlt Münkler, Herfried (2015): Kriegssplitter. Die Evolution der Gewalt im 20. und 21. Jahrhundert. Berlin: Rowohlt

Nanto, Dick K./Manyin, Mark E. (2011): China-North Korea Relations, North Korean Review, 7 (2), 94-101

Narang, Vipin (2009): Posturing for Peace? Pakistan's Nuclear Postures and South Asian Stability, International Security, 34 (3), 38-78

Narang, Vipin/Panda, Ankit (2020): North Korea - Risks of Escalation, Survival, 62 (1), 47-54

Newman, Edward (2004): The 'New Wars' Debate: A Historical Perspective Is Needed, Security Dialogue, 35 (2), 173-189

Niksch, Larry A. (2010): North Korea's Nuclear Weapons Development and Diplomacy. Washington, D.C.: Congressional Research Service

Noland, Marcus (2009): The (Non-) Impact of UN Sanctions on North Korea, Asia Policy, 4 (7), 61-88.

Paret, Peter, Hrsg. (1986): Makers of Modern Strategy. From Machiavelli to the Nuclear Age. Princeton, N.J.: Princeton University Press

Patalano, Allesio/Manicom, James (2014): Rising Tides - Seapower and Regional Security in Northeast Asia, The Journal of Strategic Studies, 37 (3), 335-344

Pollack, Jonathan D. (2017): No Exit. North Korea, Nuclear Weapons, and International Security. London: Routledge for IISS

Posen, Barry R. (1984): The Sources of Military Doctrine. France, Britain, and Germany between the World Wars. Ithaca und London: Cornell University Press.

Posen, Barry R. (1991): Inadvertent Escalation: Conventional War and Nuclear Risks. Ithaca: Cornell University Press

Posen, Barry R. (2013): Pull Back - The Case for a Less Activist Foreign Policy, Foreign Affairs, 92 (1), 116-128

Pritchard, Charles L. (2007): Failed Diplomacy: The Tragic Story of How North Korea Got the Bomb. Washington, D.C.: Brookings Institution

Ratner, Ely (2013): Rebalancing to Asia with an Insecure China, The Washington Quarterly, 36 (2), 21-38

Reid, Brian Holden (2008): J.C.F. Fuller's Theory of Mechanized Warfare, in: Mahnken, Thomas G./Maiolo, Joseph A. (Hrsg.): Strategic Studies. A Reader. London und New York: Routledge, 108-120

Roberts, Brad (2016): The Case for U.S. Nuclear Weapons in the $21^{\text {st }}$ Century. Stanford, Cal.: Stanford University Press

Roberts, Brad (2020): On Adapting Nuclear Deterrence to Reduce Nuclear Risk, Deadalus, 149 (1), 69-83

Rosen-Königsbuch, Jacob (2019): Wer wird das kriegsgeschundene Syrien wiederaufbauen? China könnte ein Kandidat sein, Sirius - Zeitschrift für strategische Analysen, 3 (1), 73-75

Rothenberg, Gunther E. (1986): Moltke, Schlieffen, and the Doctrine of Strategie Envelopment, in: Paret 1986, 296-325

Rubin, Uzi (2020): Iran's Missiles and Its Evolving "Rings of Fire". Ramat Gan, Isr.: Bar Ilan University, BESA Center for Strategic Studies

Sagan, Scott D. (1985): Nuclear Alerts and Crisis Management, International Security, 9 (4), 99-139.

Sagan, Scott D. (1991): Reducing the Risk. A New Agenda for Military-to-Military Talks, Arms Control Today, 21 (6), 16-21 
Sagan, Scott D. (1993): The Limits of Safety: Organizations, accidents, and nuclear weapons. Princeton: Princeton University Press.

Salek, Naeem (2009): The Genesis of South Asian Nuclear Deterrent: A Pakistani Perspective. Oxford: Oxford University Press

Sapper, Manfred (2008): Den Krieg überwinden. Jan Bloch: Unternehmer, Publizist, Pazifist, Osteuropa, 58 (8-10), 303-312.

Schmucker, Robert/Schiller, Markus (2017): Nordkoreas Raketenprogramm. Drohung oder Bluff?, Sirius -Zeitschrift für strategische Analysen, 1 (4), 319-341

Shaheen, Salma (2019): Nuclear Command and Control Norms. A Comparative Study. London und New York: Routledge

Shambough, David (2002): Modernizing China's Military - Progress, Problems and Prospects. Berkeley, Cal.: University of California Press

Snyder, Jack (1984): The Ideology of the Offensive. Military Decision Making and the Disasters of 1914. Ithaca, N. Y.: Cornell University Press

Steinbruner, John D. (1984): Launch Under Attack, Scientific American, 250 (1), 37-47

Storz, Dieter (1992): Kriegsbild und Rüstung vor 1914. Europäische Landstreitkräfte vor dem Ersten Weltkrieg. Herford: Mittler Verlag

Tannenwald, Nina (2020): Life beyond Arms Control: Moving toward a Global Regime of Nuclear Restraint \& Responsibility, Deadalus, 149 (1), 205-221

Taylor, Brendan (2014): The South China Sea is not a Flashpoint, The Washington Quarterly, 37 (1), 99-111

Tellis, Ashley (2013): Balancing without Containment. A U.S. Strategy for Confronting China's Rise, The Washington Quarterly, 36 (4), 109-124

Tertrais, Bruno (2012): The Demise of Ares. The End of War as We Know It?, The Washington Quarterly, 35 (3), 7-22

Thayer, Bradley A. (1994): The Risk of Nuclear Inadvertence: A Review Essay, Security Studies, 3 (3), 428-493

Toomay, John C. (1987): Warning and assessment sensors, in: Carter/Steinbruner/Zraket 1987, 282-321
Treue, Wilhelm (1955): Dokumentation - Hitlers Denkschrift zum Vierjahresplan, Vierteljahrshefte für Zeitgeschichte, 3 (2), 184-210

U.S. Department of Defense (2019): Military and Security Developments Involving the People's Republic of China 2019. Annual Report to Congress. Washington, D.C.: Department of Defense

Van der Meer, Sicco (2018): Reducing nuclear weapons risks. A menu of 11 policy options. Den Haag: Clingendael Institut

van Tol, Jan/Gunzinger, Mark/Krepinevich, Andrew/Thomas, Jim (2010): Air-Sea Battle. A Point-of-Departure Operational Concept. Washington, D.C.: Center for Strategic and Budgetary Assessments

Wahdat-Hagh, Wahied/Krause, Joachim (2019): Die Reaktionen des Iran auf die Aufkündigung des JCPOA durch die USA, Sirius Zeitschrift für strategische Analysen, 3 (2),184-189

Wallach, Jehuda (1967): Das Dogma der Vernichtungsschlacht. Die Lehren von Clausewitz und Schlieffen und ihre Wirkungen in zwei Weltkriegen. Frankfurt a. M.: Bernard u. Graefe

Walt, Stephen M. Walt (2011): The End of the American Era, The National Interest, No. 116, 6-16

White, Hugh (2012): The China Choice. Why America Should Share Power. Victoria, AUS: Black Inc.

Wright, Thomas (2017): All Measures Short of War: The Contest for the Twenty-First Century and the Future of American Power. New Haven: Yale University Press

Zdanavičius, Liudas/Czekai, Matthew, Hrsg. (2015): Russia's Zapad 2013 Military Exercise. Lessons for Baltic Regional Security. Washington, D.C. und Riga: Jamestown Foundation und National Defence Academy of Latvia

Zraket, Charles A. (1984): Strategic Command, Control, Communications, and Intelligence, Science, New Series, 224 (4655), 1306-1311

Zuber, Terence (2003): Inventing the Schlieffen Plan. German War Planning 1871-1914. Oxford: Oxford University Press 